\title{
O Plano de Metas e a estrutura empresarial e financeira da indústria de máquinas e equipamentos no Brasil: Dedini e Romi, 1955-1961 *
}

\author{
Michel Deliberali Marson **
}

\begin{abstract}
Resumo
O Plano de Metas foi fundamental para a mudança estrutural produtiva do Brasil no final dos anos 1950, aumentando a participação relativa da indústria na economia e encadeando o desenvolvimento industrial para setores mais complexos e intensivos em tecnologia. Uma questão importante é como o Plano de Metas influenciou setores industriais específicos, como o de máquinas e equipamentos. $\mathrm{O}$ objetivo do artigo é examinar a evolução da estrutura empresarial e financeira da indústria de máquinas e equipamentos no Brasil, por meio da análise de balanços e registros de documentos na Junta Comercial da Romi e Dedini, as maiores empresas nacionais produtoras de máquinas-ferramentas e equipamentos agrícolas, respectivamente, diante das políticas econômicas derivadas do Plano de Metas, no período de 1955 a 1961 . As principais conclusões foram que as políticas do período impactaram positivamente no investimento e negativamente na rentabilidade dessas empresas nacionais de máquinas e equipamentos.
\end{abstract}

Palavras-chave: Plano de Metas; Indústria; Máquinas e equipamentos; Dedini; Romi.

\begin{abstract}
The Target Plan and the business and financial structure of the machinery and equipment industry in Brazil: Dedini and Romi, 1955-1961

The Target Plan was critical to the change in the productive structural in Brazil in the late 1950s, increasing the industry's relative share in the economy and linking industrial development to more complex and technology-intensive sectors. An important question is how the Target Plan affected specific industries, such as machinery and equipment. The aim of this paper is to examine the evolution of the business and financial structure of the machinery and equipment industry in Brazil. This is carried out through the analysis of balance sheets and document records on the Board of Trade of Romi and Dedini, the largest domestic producers of machine tools and agricultural equipment, respectively, together with the economic policies derived from the Target Plan for the period 1955 to 1961 . The main conclusions were that the policies implemented during that time had a positive impact on investment and a negative impact on the profitability of these national machinery and equipment companies.
\end{abstract}

Keywords: Target Plan; Industry; Machinery and equipment; Dedini; Romi.

JEL N16, N66, N86.

\section{Introdução}

O Plano de Metas, plano de desenvolvimento da economia brasileira implementado por Juscelino Kubitschek, foi fundamental para a mudança estrutural

\footnotetext{
*Artigo recebido em 25 de abril de 2016 e aprovado em 9 de agosto de 2017.

** Professor do Instituto de Ciências Sociais Aplicadas da Universidade Federal de Alfenas, Varginha, MG,
} Brasil. E-mail: michelmarson@yahoo.com.br. 
produtiva do Brasil no final dos anos 1950, aumentando a participação relativa da indústria na economia e encadeando o desenvolvimento industrial para setores mais complexos e intensivos em tecnologia. Uma questão importante é como o Plano de Metas influenciou setores industriais específicos, como o de máquinas e equipamentos. As trinta metas do Plano ${ }^{1}$ tiveram impacto direto e indireto para o processo de industrialização no Brasil, mas especificamente as metas 17 (mecanização da agricultura), 27 (indústria automobilística) e 29 (indústria de material elétrico e mecânica pesada) poderiam afetar diretamente as empresas de máquinas e equipamentos no Brasil. Diante disso, há a necessidade de examinar como as políticas de desenvolvimento do Plano de Metas e as demais políticas econômicas influenciaram a estrutura empresarial e financeira das empresas de máquinas e equipamentos nacionais.

Alguns autores, como Carlos Lessa, afirmam que uma das características do Plano de Metas foi o tratamento extremamente favorável à entrada de capital estrangeiro $^{2}$ (Lessa, 1982, p. 56). Nessa mesma linha, para Maria da Conceição Tavares a montagem da indústria de material de transporte e elétrico pelo grande capital internacional realocou a liderança da expansão industrial. Assim, o investimento público tornou-se complementar ao capital estrangeiro e ambos arrastavam o conjunto de investimento privado nacional (Tavares, 1998, p. 77-78). Paul Singer relatou que todas as indústrias que expandiram no período do Plano de Metas foram, com exceção da mecânica, originadas da Segunda Revolução Industrial, com aperfeiçoamento tecnológico após da Primeira Guerra Mundial. Essas indústrias tinham como condição fundamental a grande escala de produção, e no Brasil, após 1956, se desenvolveram de forma acelerada principalmente com as multinacionais. Assim, os ramos que mais cresceram no período foram aqueles com maior participação do capital estrangeiro (Singer, 2007, p. 280-281).

Entretanto, algumas políticas econômicas do período poderiam ter direta ou indiretamente favorecido a oferta interna de produtos industriais. Segundo Luiz Orenstein e Antonio Claudio Sochaczewski a política cambial foi o principal instrumento de política econômica à disposição do setor público na década de 1950 e as modificações na política cambial foram decisivas para o desenvolvimento econômico. A reforma cambial de $1953^{3}$, que criou as taxas múltiplas de câmbio, teria sido fundamental para proteção à indústria e intensificação do processo de substituição de importações. No setor específico de bens de capital, a reforma

(1) Ver Brasil (1959).

(2) O principal instrumento de política econômica era a Instrução 113 da Superintendência da Moeda e do Crédito (Sumoc) de 1955 que autorizava a entrada de capital estrangeiro via importação de máquinas e equipamentos sem cobertura cambial. Entretanto, desde 1953 o governo adotou política liberal à incorporação de poupança externa (ver Lessa, 1982, p. 58).

(3) Dada pela Lei 1807 e Instrução 70 da Superintendência da Moeda e do Crédito (Sumoc). 
tarifária e cambial de $1957^{4}$ teve como objetivo acelerar a substituição de bens de capital, subsidiando a importação de bens de capital sem prejudicar a oferta interna. Assim, a reforma de 1957 promoveu um aprofundamento da substituição de importações em estágio mais avançado da industrialização (Orenstein; Sochaczewski, 1990, p. 171-175).

Para José Serra (1982) na primeira metade dos anos 1950 foram tomadas medidas para o salto industrial posterior. A Instrução 70 da Sumoc de 1953 disciplinou a alocação de importações de forma racional em função dos interesses industriais e promoveu uma fonte de recursos adicionais para o Estado. A criação do Banco Nacional de Desenvolvimento Econômico (BNDE) em 1952 apoiaria a infraestrutura de transportes e energia. A criação da Petrobrás em 1953 promoveu o monopólio estatal da prospecção, produção e refino do petróleo. A Instrução 113 da Sumoc de 1955 permitia às empresas estrangeiras sediadas no país importarem máquinas e equipamentos sem cobertura cambial para atrair no curto prazo o investimento direto estrangeiro. No período do Plano de Metas foram criados os grupos executivos para metas setoriais e esses instrumentos foram utilizados para promover o intenso processo de industrialização liderado pelo Estado. Assim, foram instaladas as indústrias automobilística, de construção naval e material elétrico pesado e houve ampliação do setor de bens de capital, como a produção de máquinas e equipamentos e expansão das indústrias básicas, como a siderurgia, química pesada, petróleo, papel e celulose (Serra, 1982, p. 20-28).

Por outro lado, alguns autores acreditam que essas políticas gerais de incentivo ao processo de industrialização na América Latina promoveram um desenvolvimento industrial fechado, tecnologicamente atrasado e ineficiente. $\mathrm{O}$ resultado dessa ineficiência no processo de industrialização teria como causa a proteção tarifária, sistema de taxas múltiplas de câmbio, sistema de licenças para importações e participação estatal em empresas e bancos de fomento às indústrias (Haber, 2008, p. 562).

Segundo Stephen Haber (2008) o objetivo principal desse protecionismo era criar distorções para favorecer os fabricantes de manufaturas em relação aos outros setores da economia. Essas políticas (tarifas, restrições quantitativas, taxas múltiplas de câmbio) geraram consequências inesperadas e perversas. Um dos primeiros resultados desse protecionismo foi agravar o problema dos balanços de pagamentos dos países da América Latina. Apesar de o protecionismo ter resolvido o problema do balanço de pagamento no curto prazo, o crescimento da indústria de bens de consumo impulsionou o aumento da importação de bens de capital e de bens intermediários agravando o problema de balanço de pagamentos nesses países. Uma solução para esse problema foi o aumento da proteção comercial também para o setor

(4) Lei 3244 de 14 de agosto de 1957 
de bens de capital e intermediário. Outra solução foi aumentar as exportações tradicionais (produtos minerais e agropecuários), com política econômica que distorceu o sistema econômico. Assim, o que aconteceu na América Latina foi o crescimento do mercado interno, com políticas econômicas de curto prazo que fecharam esse mercado, distorcendo os incentivos de ganhos externos para os ganhos internos (Haber, 2008, p. 578).

A segunda consequência perversa do protecionismo foi a transferência de renda para as companhias multinacionais, que aumentaram sua participação de fabricação nesses países, já que com a proteção doméstica tinham dificuldade de exportar seus produtos para a América Latina, mas viram condições de aproveitar, com a fabricação doméstica, a proteção de um mercado interno em expansão. $\mathrm{O}$ resultado final foi um mercado segmentado, após uma intensa competição interna, ficando as empresas multinacionais com setores mais intensivos em tecnologia e as nacionais com setores mais tradicionais. A terceira consequência está relacionada à ineficiência dos produtores, incluindo as empresas multinacionais, na América Latina. As escolhas disponíveis para os produtores eram empregar tecnologias menos eficientes do que o padrão mundial ou tecnologias eficientes, mas com menor capacidade, por causa da estrutura de mercado da América Latina. O resultado de ambas as escolhas foi um custo de produção mais elevado se comparado à produção em um mercado sem distorções, transferido para o consumidor final em forma de preços mais elevados (Haber, 2008, p. 579-580).

Para Haber (2008) o processo de industrialização liderado pelo Estado tinha criado distorções profundas nas economias da América Latina até o início dos anos 1970. O aprofundamento desse processo foi baseado em empréstimos externos abundantes nos anos 1970, que provocaram a crise da dívida dos anos 1980 e deu fim ao modelo adotado (Haber, 2008, p. 582-583). Assim, não há um consenso na historiografia econômica sobre os resultados das políticas econômicas para a industrialização nos países da América Latina.

Também não há um consenso de que havia uma política efetiva para o setor de máquinas e equipamentos nacionais nos anos 1950 no Brasil. Estudos mais gerais afirmam que apesar de haver previsão de financiamento privado por capitalização própria das empresas, subvenção pública e financiamento de entidades governamentais no Plano de Metas, a maioria das metas foi financiada pelo setor público (governos federal e estadual) e o Banco Nacional de Desenvolvimento Econômico (BNDE) (Araújo et al., 2011, p. 126). Para Fishlow, ao analisar o processo de industrialização por substituição de importações no período dos anos 1950, além da redução da participação dos bens duráveis de consumo nas importações totais, outra estratégia de substituição de importações foi o maior incentivo à indústria interna de bens de capital, principalmente de equipamentos avançados com modificações para atender às necessidades internas (Fishlow, 1972, 
p. 52-53). Outros estudos mais específicos afirmam que as medidas de política econômica tomadas no início dos anos 1950, ainda no governo Vargas, terão efeito no final da década expandindo a indústria de bens de consumo e bens de capital, mas ainda em 1955 não existia uma política específica para o desenvolvimento da indústria de bens de capital no Brasil (Lago et al, 1979, p. 97). Nessa mesma linha, Nathaniel Leff (1968) e Joel Bergsman (1970) concluem que a produção de equipamentos no Brasil não recebeu qualquer proteção tarifária antes dos anos 1960 (Leff, 1968, cap. VI; Bergsman, 1970, cap. III).

Assim, no intuito de lançar luz à discussão, faz-se necessário um estudo sobre a estrutura empresarial e financeira da indústria nacional de máquinas e equipamentos do Brasil diante das políticas econômicas do período.

O objetivo do artigo é examinar a evolução da estrutura empresarial e financeira da indústria de máquinas e equipamentos no Brasil, por meio da análise de balanços e registros de documentos na Junta Comercial da Romi e Dedini, as maiores empresas nacionais produtoras de máquinas-ferramentas, principalmente tornos, e equipamentos agrícolas, respectivamente, diante das políticas econômicas derivadas do Plano de Metas, no período de 1955 a 1961. Questões sobre a rentabilidade e investimentos das empresas no setor serão relacionadas às políticas econômicas do período.

A próxima seção examinará a evolução da indústria de máquinas e equipamentos no Brasil diante das políticas do Plano de Metas relatadas pela historiografia geral e específica do setor. A segunda seção é a contribuição empírica do trabalho para a literatura realizando estudo de caso de duas das maiores empresas do setor de bens de capital nacional no período do Plano de Metas. A última seção resume as principais conclusões do artigo.

\section{O Plano de Metas e a indústria de bens de capital e de máquinas e equipamentos no Brasil nos anos 1950}

A presente seção tem como objetivo examinar as metas específicas do Plano de Metas relacionadas à indústria de máquinas e equipamentos para identificar os mecanismos específicos de apoio a esse setor. Primeiramente revisaremos os resultados e as características gerais do plano para depois focar nas metas específicas à indústria de máquinas relacionadas ao setor privado nacional e ao capital estrangeiro ${ }^{5}$. Depois de examinar o Plano abordaremos a evolução da indústria no período.

No período de 1949 e 1959 ocorreu a mais intensa mudança estrutural da produção industrial brasileira até então. As indústrias que mais cresceram foram as

(5) Para uma análise minuciosa das características do Plano de Metas ver Lafer (2002, especialmente capítulos 2 e 3) e Lessa (1982). 
de plástico, equipamento de transporte, material elétrico, produtos químicos e metalurgia. Esse crescimento foi baseado em substituição de importações de setores novos, como o de equipamentos de transporte, máquinas elétricas e produtos químicos, mas também houve uma significativa substituição de importações global (Fishlow, 1972, p. 48-51).

Para Albert Fishlow (1972) um dos componentes importantes da nova substituição de importações foi o papel do capital estrangeiro, principalmente na transferência tecnológica para os setores modernos e o autofinanciamento do equipamento de capital, em moeda estrangeira (Fishlow, 1972, p. 51). José Serra (1982) também afirmou o protagonismo do capital estrangeiro, com as empresas estatais, no tripé (empresas do Estado, capital privado e capital estrangeiro) em que se baseou a industrialização brasileira desde meados dos anos 1950. As empresas transnacionais foram as grandes responsáveis pelo salto da industrialização para ramos "pesados" de bens de produção e de consumo duráveis. As principais características do processo de transnacionalização da indústria brasileira foram que as empresas estrangeiras concentraram-se na indústria de transformação, controlando $30 \%$ do estoque de capital, e nos setores mais dinâmicos, sendo responsáveis por $85 \%$ das vendas dos bens duráveis de consumo e $57 \%$ das vendas dos bens de capital em 1970. Outra característica das empresas transnacionais era a operação com maior escala, intensidade de capital, oligopolização e produtividade mais elevada do que as privadas nacionais. Para diminuir o conflito de interesses entre as empresas transnacionais e as privadas nacionais havia um alto grau de complementaridade entre elas, com associação tecnológica e uma grande diversidade entre as próprias empresas transnacionais, com nacionalidade e ramos diferentes (Serra, 1982, p. 18-20).

Por outro lado, o estudo de Susan Cunningham (1982), apesar de afirmar que o estilo da industrialização brasileira entre os anos 1950 e 1980 direcionou um papel subsidiário para as empresas privadas nacionais, já que as mudanças estruturais dos anos 1950 resultaram em diminuição da estrutura global da propriedade das firmas privadas nacionais, diante do aumento do controle estatal na economia e da penetração das multinacionais, mostrou também que há clara evidência de que as empresas brasileiras de todos os tamanhos foram capazes de se estabelecer ou expandir, em considerável número, em setores dinâmicos como o de bens de capital (Cunningham, 1982, p. 41). A indústria privada nacional não era homogênea, sendo largamente composta de pequenas e médias empresas, principalmente de propriedades individuais operando em setores de bens de consumo não duráveis, e empresas nacionais de grande escala, com substancial representação no setor de indústrias dinâmicas e tradicionais (Cunningham, 1982, p. 8) ${ }^{6}$.

(6) O trabalho de Cunningham (1982) mostra a importância das empresas privadas nacionais no processo de industrialização do Brasil entre 1950 e 1980 mesmo em setores dinâmicos como os bens de capital. O trabalho apresenta minuciosos estudos de casos dessas empresas. 
As empresas privadas nacionais poderiam ter se beneficiado de novos elementos no sistema industrial, como a expansão geral da base industrial, especialmente oferta de energia e matérias primas; grandes fundos, públicos e privados, disponíveis para a indústria; legislação protecionista; introdução de políticas para o aumento do componente doméstico no produto industrial; rápida transferência tecnológica e redução do risco através de associação com empresas públicas e estrangeiras (Cunningham, 1982, p. 7-8).

Os estímulos da política econômica do Plano de Metas para os investimentos privados estavam atrelados à redução dos custos monetários do investimento, com a obtenção de financiamentos externos, créditos de longo prazo ofertados pelo Banco Nacional de Desenvolvimento Econômico, com baixas taxas de juros e amplo período de carência e amortização, e reserva de mercado interno para novos setores industriais, com o controle do câmbio e proteção mais eficiente depois da reforma tarifária de 1957 (Lessa, 1982, p. 71-72).

A reforma cambial de 1953 que substituiu um sistema de taxa de câmbio fixa sobrevalorizada com licenças de importações para um sistema de taxas múltiplas de câmbio $^{7}$ poderia ter sido favorável para a indústria de máquinas e equipamentos nacional já que teria aumentado a proteção desse setor. Esse resultado pode ter sido favorável porque a taxa de câmbio para a importação de máquinas e equipamentos tinha sofrido uma depreciação implícita (categoria I para máquinas agrícolas e categoria III para ferramentas) em relação ao período anterior ${ }^{8}$, ou seja, as importações de máquinas agrícolas e ferramentas ficaram mais caras em moeda nacional aumentando a proteção da indústria interna em relação às importações.

Outra medida favorável para a proteção da indústria de máquinas nacional pode ter sido a reforma cambial e tarifária de agosto de 1957. A reforma cambial simplificou para duas as categorias de importação, a geral e a especial. Os bens de capital incluídos na categoria geral foram os essenciais sem similar nacional e os

(7) As taxas de câmbio eram negociadas em leilão, ou seja, determinadas pelo mercado, em 5 categorias para importação, mas sofriam influência já que era cobrado um ágio pelo Governo. Na prática, o que era negociado em bolsa era a promessa de venda de câmbio que dava direito ao certificado de câmbio e, após a cobrança do ágio, à licença para a importação (Vianna, 1990, p. 138-143).

(8) As importações de equipamentos foram classificadas na categoria III, em geral, mas também nas categorias I, II e IV. As máquinas agrícolas foram classificadas na categoria I e as ferramentas na categoria III para taxas de câmbio de importação (Almeida, 1983, p. 6-7; Doellinger et al., 1977, p. 28). A taxa de câmbio estava fixada em 18,5 cruzeiros por dólar antes da reforma de 1953. A média da taxa de câmbio foi de 31,77 cruzeiros por dólar entre outubro e dezembro de 1953 e de 39,55 cruzeiros por dólar em 1954 para a categoria I e de 44,21 cruzeiros por dólar entre outubro e dezembro de 1953 e de 57,72 cruzeiros por dólar em 1954 para a categoria III (Vianna, 1990, p. 140). Assim, ocorreu uma depreciação nominal do câmbio de 113,78\% para a categoria I de importação e uma depreciação nominal do câmbio de $212 \%$ para a categoria III de importação entre o período anterior a reforma cambial e 1954. Como o aumento de preços industriais nacionais no período foi de 31,55\%, (ver Malan, 1977, p. 516) ocorreu uma depreciação real da taxa de câmbio, encarecendo a importação desses produtos em relação ao período anterior à reforma cambial. 
incluídos na categoria especial eram os que já apresentavam oferta doméstica suficiente (Almeida, 1983, p. 8). Assim, parece que houve um subsídio para a importação de bens de capital sem prejudicar a oferta interna ${ }^{9}$. A reforma tarifária tinha como objetivo introduzir as tarifas ad valorem para prover a proteção sem a perda por causa da inflação como ocorre quando a tarifa é específica ${ }^{10}$.

Por outro lado, uma das políticas que poderiam ter desfavorecido a indústria de máquinas e equipamentos nacional era a Instrução 113 da Sumoc, a qual autorizava a importação de equipamentos sem cobertura cambial. Assim, apesar de estimular a implantação de setores modernos na economia, também significava um aumento da concorrência interna e um vazamento de mercado que poderia ter sido atendido pela produção nacional (Almeida, 1983, p. 8). Dessa forma, apenas 11,2\% do investimento direto estrangeiro via Instrução 113 da Sumoc foi para o setor de fabricação de máquinas e equipamentos entre 1955 e 1963, sendo que a maior parte $(38,1 \%)$ foi para a fabricação e montagem de veículos automotores, reboques e carrocerias (Caputo; Melo, 2009, p. 528). A implantação da indústria automobilística e de componentes promoveu vários efeitos na indústria, mas principalmente criou ou ampliou o mercado para uma série de bens de capital, como o setor de máquinasferramentas $^{11}$ (Almeida, 1983, p. 12). De qualquer forma, os possíveis incentivos aos estrangeiros dados pela Instrução 113 da Sumoc, como menor custo para o investimento, foram compensados pela extensão às firmas nacionais de vantagens similares, concedidas sobre créditos de fornecedores no exterior para a importação de equipamentos (Fishlow, 1972, p. 51).

A partir de agora concentraremos a atenção para as metas específicas do Plano de Metas que poderiam afetar a indústria de máquinas e equipamentos. A primeira meta que poderia estar atrelada à indústria de máquinas era a mecanização da agricultura (meta 17 do Plano de Metas) que tinha como objetivo aumentar o número de tratores em uso no país. A meta revisada do plano foi alcançada, mas com a importação de tratores. Apenas após 1960 a produção de tratores foi incluída na meta da indústria de veículos. Os incentivos para o alcance da meta de mecanização

(9) A média da taxa de câmbio para a categoria III de importação (onde se concentrava a maior parte dos bens de capital) foi de 106,34 cruzeiros por dólar entre janeiro e agosto de 1957 (Bastos, 2012, p. 442) para 179,67 por dólar na categoria especial entre setembro e dezembro de 1957 (Almeida, 1983, p. 9), ocorrendo assim uma depreciação de 68,96\% na taxa de câmbio para importação nesse período, com perda de poder de compra em moeda nacional para a importação das máquinas e equipamentos com similar nacional.

(10) Para alguns autores ocorreu melhora na proteção efetiva da indústria no geral com a reforma tarifária, mas a política tarifária para os bens de capital continuou muito liberal, ou seja, os impostos pagos na importação de bens de capital raramente excediam 10\% (Almeida, 1983, p. 9).

(11) Para Fabio Erber et al. (1974) em vários subsetores, como o de máquinas-ferramentas, equipamentos para o setor de açúcar e álcool e outros, praticamente não houve a entrada de capitais estrangeiros, sendo possível continuar com a prática de copiar equipamentos do exterior e produzi-los com tecnologia de domínio público (Erber et al., 1974, p. 16-17). 
da agricultura estavam relacionados aos avais do BNDE para empréstimos em moeda estrangeira e a quota no orçamento cambial da Sumoc (Lafer, 2002, p. 131-132).

As duas metas mais importantes do plano relacionadas à indústria de máquinas e equipamentos foram a da indústria automobilística (meta 27) e a da indústria mecânica pesada e de material elétrico (meta 29). A meta revista da indústria automobilística era a produção de 140 mil veículos a motor em 1960. No período de 1957 e 1960 a produção efetiva chegou a 92\% da meta estabelecida. A responsabilidade de administração da meta ficou com o Grupo Executivo da Indústria Automobilística (Geia). Os benefícios para essa meta foram autorizações de investimentos com taxas de câmbio preferenciais para a importação de equipamentos pela Instrução 113 da Sumoc, financiamentos de longo prazo pelo BNDE, isenções tarifárias e restrições à importação de componentes estrangeiros fabricados no país (Lafer, 2002, p. 141-143). A meta da indústria mecânica pesada e de material elétrico, administrada pelo Grupo Executivo da Indústria de Maquinaria Pesada (Geimape), tinha como objetivo expandir a indústria de bens de capital devido à demanda derivada de outras metas do plano. Os incentivos para essa meta foram recursos do $\mathrm{BNDE}^{12}$ para a produção de equipamentos elétricos ${ }^{13}$, outros incentivos para a indústria mecânica ${ }^{14}$, elevação das tarifas sobre equipamentos já produzidos no país e eliminação das taxas de câmbio preferenciais para a importação de equipamentos já fabricados no país (Lafer, 2002, p. 143-145).

Depois de examinar os principais benefícios do Plano de Metas para a indústria de máquinas e equipamentos, o restante dessa seção tratará da evolução da indústria de máquinas e equipamentos, especificamente de máquinas-ferramentas, subsetor de atuação da Romi, e de máquinas agrícolas, relacionada à indústria do açúcar e álcool, subsetor da Dedini, ao longo dos anos 1950, que serão temas de estudos de casos na próxima seção.

No início dos anos 1960, a Cepal publicou um estudo sobre a indústria de máquinas e ferramentas no Brasil que afirmava que essa indústria apresentava características modernas e com um variado mercado. A indústria de máquinasferramentas compreendia em torno de 114 estabelecimentos, empregava cerca de 5.000 pessoas, com produção aproximada de 26 milhões de dólares. Uma das características gerais apresentadas por essa indústria era a alta concentração dos

(12) Alguns autores afirmam ter pouca importância o fornecimento de crédito pelo BNDE para a indústria de bens de capital nos anos 1950 porque nos seus primeiros anos o banco voltou-se a sua atuação para o fornecimento de crédito para o setor público (principalmente para setores de infraestrutura como energia elétrica e transportes) mudando de postura apenas após 1968 quando ampliou sua atuação para o setor privado (Almeida, 1983, p. 13; Lago et al., 1979, p. 108).

(13) Os recursos foram para as seguintes empresas: AEG, Arno, Brown-Boveri, Irne, Pirelli e Fundição Tupi (Lafer, 2002, p. 114).

(14) Os incentivos foram para as seguintes empresas: Mecânica Pesada S.A., Cobrasma, Funge, Cia. Brasileira de Caldeiras, etc. (Lafer, 2002, p. 114). 
estabelecimentos (88\%) e pessoas ocupadas (94\%) no estado de São Paulo, principalmente na capital e região do ABC (cidades de Santo André, São Bernardo e São Caetano do Sul), com estabelecimentos menores, e no interior do estado (principalmente entre Jundiaí e São Carlos), com estabelecimentos maiores. Outra característica foi a alta proporção de estabelecimentos que fabricavam máquinasferramentas que mantinham linhas de produção anexas a esse setor, ou seja, nem todas as empresas se dedicam exclusivamente à produção de máquinas-ferramentas, como tornos, fresadoras, serras, e outras, já que uma parte das empresas começou a se interessar pela produção depois de atuar em outros setores mecânicos. O estudo também comparou o tamanho dos estabelecimentos produtores de máquinasferramentas no Brasil com países desenvolvidos (França, Estados Unidos e GrãBretanha) ficando clara a baixa proporção (apenas 8,9\%) de estabelecimentos brasileiros com empresas de alta eficiência produtiva (empregando acima de 100 pessoas) com relação aos países desenvolvidos (proporção de 20 a 30\%) (Cepal, 1962, p. 29-33).

Outro estudo do início dos anos 1960 também afirmou que a indústria de máquinas-ferramentas no Brasil apresentava produção altamente satisfatória de tipos de produtos semiautomáticos e alguns certos setores automáticos, apesar de não existir produção de máquinas especiais para trabalho de metais destinados à fabricação de determinadas peças e artigos metálicos. O estudo apresenta informações detalhadas de 106 empresas de máquinas-ferramentas no Brasil (Banas, 1962, p. 129-172). Das empresas produtoras de máquinas-ferramentas em 1962, $43 \%$ foram fundadas depois do início dos anos 1950 (26\% entre 1950 e 1955 e $17 \%$ após 1956). Assim, essa indústria não era nova no início dos anos 1960 já que existiam fabricantes instalados no país desde os anos $1920^{15}$, mas ocorreu uma modernização e ampliação nos anos 1950 e o mais interessante é que o maior número de fundação de empresas foi anterior a 1956, apesar da potencialização da produção com a instalação da indústria automobilística (Banas, 1962, p. 129, 133-134).

A indústria de máquinas para usinas de açúcar e álcool estava plenamente capacitada para atender às necessidades das empresas desse setor no início dos anos 1960. Nesse período, o setor apresentava 8 empresas produtoras de máquinas e equipamentos, sendo 3 delas do grupo Dedini (M. Dedini, Mausa e Codistil) (Banas, 1962, p. 173, 175). Como será visto na próxima seção, na indústria de máquinas para o setor de açúcar e álcool, parece que mudanças específicas dentro do setor ao longo dos anos 1950 foram mais importantes do que as políticas do Plano de Metas para explicar sua evolução no período.

(15) Algumas empresas apresentam fundação no final do século XIX, mas nesse período produziam outros produtos mecânicos. 
O Plano de Metas e a estrutura empresarial e financeira da indústria de máquinas e equipamentos...

\section{A evolução da estrutura empresarial e financeira da indústria de máquinas e equipamentos nacional: o caso da Dedini e da Romi}

O objetivo desta seção é examinar a evolução da estrutura empresarial e financeira de duas empresas da indústria de bens de capital nacional, a Dedini e a Romi. Outra análise que será feita é da evolução do desempenho econômicofinanceiro até 1961, identificando-se os principais determinantes para a evolução do capital e o sucesso das duas empresas no ramo específico de atuação.

As duas empresas iniciaram suas atividades com uma estrutura pequena, como empresa individual ${ }^{16}$. As empresas nesse período eram baseadas em uma administração familiar e assim permaneceram até os anos 1960. Mesmo quando as empresas tornaram-se sociedades limitadas, os sócios eram dos círculos de relações próximos às famílias que comandavam as empresas. É interessante ressaltar que, mesmo quando as empresas tornaram-se sociedades anônimas, a admissão na sociedade continuou a ser definida pelas relações familiares.

A Tabela 1 mostra a evolução do capital da Dedini desde sua fundação em 1920 até 1961, com as alterações do capital e a origem dessa alteração ${ }^{17}$.

Tabela 1

Evolução do capital social da Dedini, 1920-1961 (mil-réis ou cruzeiros correntes)

\begin{tabular}{c|c|c|c|c}
\hline & \multicolumn{3}{|c}{ Dedini } \\
\hline Anos & Inicial & \multirow{2}{*}{ Alteração } & Final & Origem da alteração do capital \\
\hline 1920 & 8.500 & & & Lucros \\
\hline 1922 & 8.500 & 1.500 & 10.000 & Lucros \\
\hline 1926 & 10.000 & 40.000 & 50.000 & Lucros \\
\hline 1929 & 50.000 & 100.000 & 150.000 & Lucros \\
\hline 1932 & 150.000 & 150.000 & 300.000 & Lucros \\
\hline 1935 & 300.000 & 200.000 & 500.000 & Lucros \\
\hline 1937 & 500.000 & 500.000 & 1.000 .000 & Lucros \\
\hline 1945 & 1.000 .000 & 5.000 .000 & 6.000 .000 & Lucros \\
\hline 1951 & 6.000 .000 & 24.000 .000 & 30.000 .000 & Dinheiro e reservas \\
\hline 1952 & 30.000 .000 & 30.000 .000 & 60.000 .000 & Bens \\
\hline 1955 & 60.000 .000 & 30.000 .000 & 90.000 .000 & Créditos \\
\hline 1958 & 180.000 .000 & 90.000 .000 & 180.000 .000 & Reavaliações, reservas e ac̃es de terceiros \\
\hline 1961 & 234.000 .000 & 150.000 .000 & 384.000 .000 & \\
\hline
\end{tabular}

Fonte: São Paulo. Diário Oficial do Estado de São Paulo (vários anos); Negri (1977, p. 223).

(16) A Dedini começou com uma sociedade dos irmãos Dedini, mas depois do falecimento de Armando Casare Dedini, em 1926, irmão de Mário, a empresa tornou-se individual.

(17) Os valores das Tabelas 1 e 2 são apresentados em sua forma corrente, original, como aparecem nos documentos, ou seja, nominais, porque o principal objetivo é identificar a origem das alterações do capital social das empresas. Para uma análise da evolução do capital social das empresas ao longo do tempo, o Gráfico 1 deve ser observado. 
Da fundação da oficina dos Irmãos Dedini em 1920 até a empresa tornar-se uma sociedade por quotas em outubro de 1945, as alterações de capital tiveram origem nos lucros acumulados da atividade industrial. Em 1945, o capital foi aumentado com recursos próprios de Mário Dedini e a inclusão de novos sócios. A composição dos sócios, com os respectivos capitais, se dispôs do seguinte modo: Mário Dedini, com 33\% do capital da empresa, seus filhos Armando Dedini, Ada Dedini Ometto, Nida Dedini Ricciardi, com 16\% cada um, seu sobrinho Leonardo Dedini, com $8 \%$ e seu genro Dovílio Ometto, filho de Pedro Ometto, amigo de Mário, com 8\%. Assim, do novo capital, apenas a parcela de Dovílio parece não pertencer aos lucros gerados pela própria empresa (Negri, 1977, p. 54).

Em 1950, a M. Dedini \& Cia. tornou-se sociedade anônima, com a denominação de M. Dedini S.A. - Metalúrgica. A evolução do capital entre 1950 até 1955 se deu com os lucros acumulados na atividade da empresa, com aumento de recursos próprios dos sócios, possivelmente recursos com origem na própria empresa, ou seja, reservas da empresa. Em 1955 houve reavaliações dos valores dos ativos, aumento de capital proveniente de reservas da empresa e subscrição de ações de terceiros. Em 1958, houve um novo aumento de capital, agora com a incorporação de bens e apenas em 1961 a empresa utilizou créditos para o aumento do seu capital.

Em resumo, até os anos 1960, quando a Dedini apresentava-se como líder do mercado de máquinas e equipamentos para o setor canavieiro, a evolução do capital foi gradual conforme a evolução do mercado. A origem do capital para o crescimento da empresa foi proveniente em grande parte de recursos internos à empresa, notadamente de lucros e reservas acumuladas. A administração da Dedini, mesmo com a transformação da empresa em sociedade anônima, continuou familiar. Em 1961, a diretoria da M. Dedini S.A. - Metalúrgica era composta por Mário Dedini, diretor-presidente, Armando Dedini, Dovílio Ometto e Leopoldo Dedini, diretores (São Paulo. Diário Oficial de São Paulo, 11/04/1962, p. 82).

A Tabela 2 mostra a evolução do capital da Romi, desde sua fundação até 1961, com alterações do capital e a origem dessa alteração.

Da fundação da garagem Santa Bárbara de Emílio Romi em 1929 até a transformação da empresa em Máquinas Agrícolas Romi Ltda., sociedade por quotas, em 1938, nota-se que as alterações do capital tiveram origem nos lucros da atividade industrial e comercial da empresa. Em 1938, o aumento do capital foi realizado com recursos de Américo Emílio Romi e a entrada de novos sócios. Em junho de 1938 a sociedade estava composta da seguinte forma: Américo Emílio Romi, com $66 \%$ do capital, Carlos Chiti, filho do primeiro casamento de Olímpia Gelli Romi, mulher de Américo Emílio, com 16,5\% do capital e Oscar Berggren, de Americana, com outros 16,5\%. Oscar retirou-se no mesmo ano da sociedade transferindo suas quotas para Américo Emílio. Em 1943 houve um novo aumento do capital da empresa, novamente com recursos dos próprios sócios, provenientes da própria atividade econômica e da admissão de novos sócios. Nessa data a representação societária da empresa estava distribuída em $80 \%$ do capital 
O Plano de Metas e a estrutura empresarial e financeira da indústria de máquinas e equipamentos...

pertencente a Américo Emílio Romi, $10 \%$ pertencente a Baptista Riceti, de São Carlos, 6,5\% de Plácido Ribeiro Ferreira e 3\% de Alfredo Braga.

Em 1946, houve duas alterações para aumentar o capital da empresa, as duas com recursos de novos sócios e recursos de Américo Emílio. Mas esses sócios eram filhos de Américo Emílio, determinando que esse aumento fosse com recursos da acumulação da própria empresa. Na primeira alteração do capital em 1946, foi admitido Álvares Romi, e na segunda foram admitidos Carlos Chiti, que havia se retirado em 1942, Romeu Romi e Julieta Romi. O outro filho de Américo Emílio, Giordano Romi, foi admitido em janeiro de 1947. Ainda nesse ano e em 1948 foram feitas novas alterações no capital social da empresa com recursos dos próprios sócios. Entre 1953 e 1954, as origens do aumento do capital foram os lucros acumulados pela empresa, a incorporação de um imóvel de Américo Emílio Romi e a admissão de novos sócios: Flora Sans Romi e Maria Conceição Pimentel, respectivamente, esposa de Álvares e Giordano Romi. Assim, até 1955 a maior parte do aumento do capital da empresa deu-se com recursos gerados dentro da atividade econômica e incorporação de novos sócios pertencentes à família Romi. Antes da empresa se tornar sociedade anônima, sua composição societária era a seguinte: Américo Emílio Romi com 57\% do capital, Carlos Chiti com 11\%, Álvares Romi e Giordano Romi com 9,5\% cada, Romeu Romi e Julieta Romi Zanaga com 5,5\% cada, Flora Sans Romi e Maria Conceição Pimentel Romi com 1\% cada.

Tabela 2

Evolução do capital social da Romi, 1930-1961 (mil-réis ou cruzeiros correntes)

\begin{tabular}{c|c|c|c|c}
\hline \multicolumn{3}{|c}{} & \multicolumn{2}{c}{ Romi } \\
\cline { 1 - 2 } Anos & Inicial & \multirow{2}{*}{ Alteração } & Final & Origem da alteração do capital \\
\hline 1930 & 2.000 & & & Lucros \\
\hline 1934 & 2.000 & 98.000 & 100.000 & Lucros \\
\hline 1935 & 100.000 & 100.000 & 200.000 & Lucros \\
\hline 1937 & 200.000 & 30.000 & 230.000 & Dinheiro e novos sócios \\
\hline 1938 & 230.000 & 70.000 & 300.000 & Dinheiro e novos sócios \\
\hline 1943 & 300.000 & 1.200 .000 & 1.500 .000 & Novo sócio \\
\hline 1946 & 1.500 .000 & 850.000 & 2.350 .000 & Dinheiro e novos sócios \\
\hline 1947 & 2.350 .000 & 2.650 .000 & 5.000 .000 & Dinheiro dos sócios \\
\hline 1947 & 6.000 .000 & 3.000 .000 & 9.000 .000 & Dinheiro dos sócios \\
\hline 1948 & 9.000 .000 & 1.000 .000 & 10.000 .000 & Lucros \\
\hline 1953 & 10.000 .000 & 12.000 .000 & 22.000 .000 & Bens (imóveis) \\
\hline 1954 & 22.000 .000 & 18.000 .000 & 40.000 .000 & Dinheiro e novos sócios \\
\hline 1955 & 45.000 .000 & 5.000 .000 & 45.000 .000 & Bens (imóveis) \\
\hline 1956 & 60.000 .000 & 76.500 .000 & 136.500 .000 & Reservas e reavaliação de bens \\
\hline 1957 & 136.500 .000 & 13.500 .000 & 150.000 .000 & Dinheiro, ações subscritas e bens (máquinas) \\
\hline 1959 & 150.000 .000 & 50.000 .000 & 200.000 .000 & Bens (máquinas) \\
\hline 1961 & 200.000 .000 & 410.000 .000 & 610.000 .000 & Bens (máquinas) e ações \\
\hline
\end{tabular}

Fonte: São Paulo. Junta Comercial de São Paulo, ver Quadro A.1, no Apêndice. 
No final de 1954, a empresa foi transformada em Máquinas Agrícolas Romi S.A. Em 1955, a origem do capital incorporado à empresa foi de bens imóveis, terrenos e prédios pertencentes a Américo Emílio Romi, que estavam sendo arrendados pela empresa. Em 1956 a evolução do capital se deu com reservas próprias e reavaliações dos valores dos ativos da empresa. Em 1957, com a exposição dos produtos da Romi na "Feira Industrial de Nova York", houve a primeira manifestação oficial de interesse de pessoas e empresas dos Estados Unidos em participar da sociedade.

O aumento do capital da empresa nessa data foi com ações subscritas em dinheiro por Américo Emílio Romi e a maior parte (74\% do aumento do capital) pela incorporação de várias máquinas de João Mammana D’Agostinho, brasileiro, mas residente nos Estados Unidos. A necessidade de adquirir máquinas especiais fez a empresa aumentar o capital social novamente em 1959, com a incorporação de novas máquinas de João Mammana D’Agostinho. Em 1961, o capital social foi elevado para colocar em prática o plano de ampliação das instalações fabris da empresa apresentado ao Grupo Executivo da Indústria Mecânica Pesada, com reservas da empresa e máquinas e equipamentos incorporados à sociedade pela The Eastern Machinery Company, de Cincinnati, Ohio, Estados Unidos (ver Quadro A.1, no Apêndice $)^{18}$. Assim, até o final da década de 1950, a totalidade do capital pertenceu à família Romi. Apenas no início dos anos 1960 a empresa abriu seu capital para o investimento externo, com a necessidade de modernização para atender um mercado mais extenso e complexo, mas o controle ainda permaneceu com a família, com Giordano Romi na presidência e os irmãos como diretores (São Paulo. Diário Oficial de São Paulo, 25/03/1962, p. 80).

O Gráfico 1 apresenta a evolução do capital social da Dedini e da Romi a preços constantes de 1961 .

Dessa forma, é possível examinar a evolução do capital social das empresas ao longo do tempo. Como é possível perceber, foi nos anos 1940 que as empresas tiveram o primeiro crescimento representativo no capital social (a Romi a partir de 1943 e a Dedini a partir de 1945). Entretanto, foi apenas na década de 1950 que as empresas ampliaram seu capital social substancialmente, tornando-se empresas líderes nos setores de máquinas e equipamentos específicos em que atuavam. O mais interessante é que esse crescimento ocorreu no governo de Getúlio Vargas, antes, portanto, do início do governo de Juscelino Kubitschek e do Plano de Metas, a partir de 1956. A ampliação substancial do capital social da Dedini ocorreu entre 1951 e

(18) O incentivo dado aos estrangeiros pela Instrução 113 da Sumoc foi compensado pela extensão às firmas nacionais de vantagens similares, sobre crédito dos fornecedores para a importação de bens de capital, concedidos no exterior (Fishlow, 1972, p. 51). 
O Plano de Metas e a estrutura empresarial e financeira da indústria de máquinas e equipamentos...

1955, e da Romi entre 1953 e $1956^{19}$. Entre 1956 e o início dos anos 1960, o capital social em termos reais da Dedini caiu (com exceção de 1958 e 1961, em que ocorreram aumentos). A Romi também apresentou queda do capital social real entre 1957 e 1960, com aumento apenas em 1961.

Gráfico 1

Evolução do capital social da Dedini e da Romi, 1920-1961 (em cruzeiros constantes de 1961)

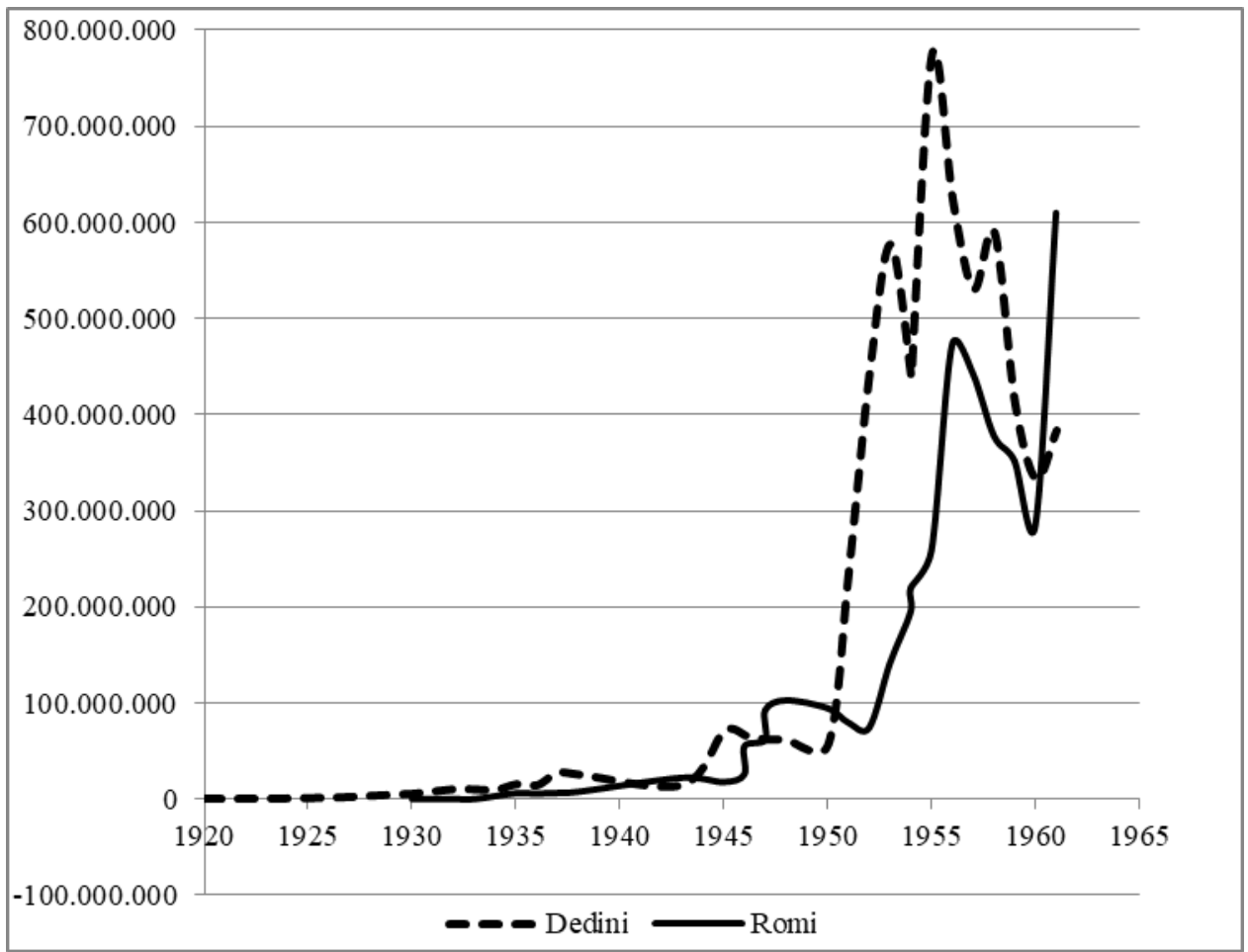

Nota: Os valores das Tabelas 1 e 2 foram deflacionados pelo índice de preços de produtos industriais de Malan et al. (1977, p. 516).

Fonte: Tabelas 1 e 2.

A partir da transformação das empresas em sociedade anônima é possível realizar uma análise mais detalhada da evolução econômico-financeira. A Tabela 3 reúne alguns indicadores da Dedini na década de 1950. Esse período é importante porque a Dedini é a maior empresa do mercado fornecendo praticamente todos os equipamentos necessários para o setor canavieiro e também é quando termina o ciclo de transformações na agroindústria canavieira. A partir da segunda metade dos anos 1950, o número de novas usinas cresceu lentamente, ao contrário do período anterior.

(19) O aumento substancial do capital social da Dedini ocorreu depois da empresa tornar-se sociedade anônima em 1950. Já no caso da Romi esse aumento começou antes da empresa tornar-se sociedade anônima no final de 1954. 
A expansão do setor canavieiro é realizada mais com modernizações das usinas existentes do que com a construção de novas usinas (Negri, 1977, p. 82-85) ${ }^{20}$.

Tabela 3

Análise econômico-financeira da M. Dedini S.A. - Metalúrgica, 1950-1961

\begin{tabular}{|c|c|c|c|c|c|c|c|c|c|c|c|c|}
\hline Índices & 1950 & 1951 & 1952 & 1953 & 1954 & 1955 & 1956 & 1957 & 1958 & 1959 & 1960 & 1961 \\
\hline $\begin{array}{l}\text { Liquidez } \\
\text { corrente }\end{array}$ & 6,93 & 3,24 & 2,82 & 2,15 & 2,00 & 2,15 & 2,29 & 2,27 & 1,93 & 2,40 & 1,36 & 1,43 \\
\hline $\begin{array}{l}\text { Liquidez } \\
\text { imediata }\end{array}$ & 1,01 & 0,46 & 0,09 & 0,04 & 0,04 & 0,08 & 0,01 & 0,01 & 0,06 & 0,16 & 0,03 & 0,03 \\
\hline $\begin{array}{c}\text { Imobilização } \\
\text { do capital }\end{array}$ & 0,31 & 0,28 & 0,19 & 0,16 & 0,15 & 0,16 & 0,27 & 0,28 & 0,35 & 0,30 & 0,51 & 0,41 \\
\hline $\begin{array}{c}\text { Quociente } \\
\text { cobertura total }\end{array}$ & 9,62 & 4,10 & 3,25 & 2,36 & 2,18 & 2,36 & 2,77 & 2,76 & 2,43 & 3,02 & 1,75 & 1,72 \\
\hline $\begin{array}{c}\text { Rentabilidade } \\
\text { PL }\end{array}$ & 0,21 & 0,24 & 0,33 & 0,12 & 0,14 & 0,12 & 0,14 & 0,11 & 0,09 & 0,21 & 0,19 & 0,21 \\
\hline $\begin{array}{l}\text { Rentabilidade } \\
\text { sobre vendas }\end{array}$ & 0,15 & 0,15 & 0,23 & 0,10 & 0,11 & 0,10 & 0,12 & 0,07 & 0,05 & 0,08 & 0,07 & 0,07 \\
\hline $\begin{array}{c}\text { Rentabilidade } \\
\text { do ativo }\end{array}$ & 0,19 & 0,18 & 0,23 & 0,07 & 0,07 & 0,07 & 0,09 & 0,07 & 0,05 & 0,14 & 0,08 & 0,09 \\
\hline $\begin{array}{c}\text { Participação } \\
\text { capital de } \\
\text { terceiros }\end{array}$ & 0,12 & 0,32 & 0,45 & 0,73 & 0,85 & 0,74 & 0,56 & 0,57 & 0,70 & 0,50 & 1,34 & 1,39 \\
\hline $\begin{array}{l}\% \text { capital de } \\
\text { terceiros no } \\
\text { ativo }\end{array}$ & 10,40 & 24,40 & 30,80 & 42,29 & 45,88 & 42,44 & 36,07 & 36,25 & 41,08 & 33,13 & 57,21 & 58,15 \\
\hline $\begin{array}{c}\% \text { capital } \\
\text { próprio no } \\
\text { ativo }\end{array}$ & 89,60 & 75,60 & 69,20 & 57,71 & 54,12 & 57,56 & 63,93 & 63,75 & 58,92 & 66,87 & 42,79 & 41,85 \\
\hline
\end{tabular}

Fonte: São Paulo. Diário Oficial de São Paulo (vários anos), ver Tabela A.1, no Apêndice.

A análise econômico-financeira da Dedini revela piora significativa nos indicadores de liquidez e rentabilidade, principalmente após 1952. O índice de liquidez corrente, ou seja, o quanto a empresa possui em ativo circulante, realizável a curto prazo para cada unidade monetária do passivo circulante (dívidas de curto prazo), diminuiu de 6,9 em 1950 para 2,0 em 1954. Apesar da piora significativa do indicador, a empresa não correu o risco de não pagamento de suas dívidas, uma vez que um indicador 2,0 indica que para cada unidade monetária em dívida a empresa possuiu duas unidades monetárias em ativos realizáveis a curto prazo.

(20) É importante notar também que o Plano de Metas não dedicava importância para a transformação estrutural do setor agropecuário. A meta de mecanização agrícola era apenas simbólica no conjunto dos objetivos do plano. Apenas 3,2\% dos recursos totais previstos no plano estavam ligados ao setor agrícola (Lessa, 1982, p. 27). 
O índice de liquidez imediata, medido pela relação entre o disponível (caixa e bancos) e o passivo corrente, revela uma piora significativa a partir de 1952. A empresa tinha à disposição em caixa e em bancos apenas $1 \%$ do total das dívidas da empresa em 1956. A empresa possivelmente teve problemas de liquidez imediata nesses anos. $\mathrm{O}$ indicador de cobertura total, que mede a possibilidade da empresa liquidar seus compromissos, também teve piora significativa a partir de 1953. Entretanto, para cada unidade monetária em dívida em 1954, a empresa possuía 2,1 unidades monetárias em ativo total, mostrando que a situação da solvência da empresa ainda estava relativamente boa. O indicador participação de capital de terceiros mostra que houve utilização crescente do capital de terceiros entre $1950 \mathrm{e}$ 1955. A estrutura do ativo indica um aumento percentual de capital de terceiros no ativo entre 1950 e 1954, diminuição entre 1955 e 1957 e novo crescimento a partir de 1960.

Entre 1950 e 1955 o indicador de imobilização do capital da Dedini, medido pela relação entre o ativo permanente e o patrimônio líquido, diminuiu. Esse resultado é possivelmente explicado pelas alterações na estrutura do setor de bens de capital para o setor canavieiro no período. Apesar da diminuição, o indicador voltou a aumentar a partir de 1956.

Os indicadores de rentabilidade sobre o patrimônio líquido, vendas e ativo total, mostram uma piora significativa após 1953. Em 1952, por exemplo, a empresa teve uma rentabilidade de $33 \%$ sobre o patrimônio líquido. Esse indicador caiu para 12\% em 1953, permanecendo nesse nível até 1957. Apenas em 1959 a rentabilidade sobre o patrimônio líquido volta ao patamar de 1950 (21\%). A queda na rentabilidade da Dedini após 1953 expõe as mudanças estruturais no setor comprador de máquinas e equipamentos para o setor canavieiro. Foi nesse período que o grupo Dedini intensificou o processo de diversificação fundando empresas para atender outros setores. Essa diversificação foi impulsionada pela necessidade do grupo em diminuir a dependência do setor canavieiro ${ }^{21}$. Na principal e pioneira empresa do grupo, a $\mathrm{M}$. Dedini S.A. - Metalúrgica, também houve mudanças no sentido de diversificação da sua produção.

A Tabela 4 mostra a participação relativa das vendas da Dedini por produtos entre 1950 e 1961. Ao longo dos anos 1950 houve diminuição da participação relativa de máquinas (moendas de cana, bombas, caldeiras, aparelhos para usinas) da empresa, de 71,2\% do total das vendas em 1950 para 31,6\% em 1961, apesar de ter ocorrido uma recuperação da participação relativa das máquinas entre 1955 e 1957. As vendas de peças (peças fundidas de ferro, aço e bronze) aumentaram de $7 \%$ do total das vendas em 1950 para 14,2\% em 1956, mas diminuíram entre 1957 e 1961.

(21) Esse processo de diversificação é detalhado em Negri (1977, p. 85-91). Aqui nos concentramos na análise da principal e pioneira empresa do grupo, a metalúrgica. 
Tabela 4

Participação relativa das vendas por produtos da M. Dedini S.A. - Metalúrgica, 1950-1961 (\% do total das vendas)

\begin{tabular}{|c|c|c|c|c|c|c|c|c|c|c|c|c|}
\hline & 1950 & 1951 & 1952 & 1953 & 1954 & 1955 & 1956 & 1957 & 1958 & 1959 & 1960 & 1961 \\
\hline Peças & 7,0 & 5,9 & 5,9 & 7,8 & 10,1 & 11,1 & 14,2 & 11,1 & 9,1 & 7,2 & 7,5 & 8,1 \\
\hline Fundidas de ferro & 4,5 & 3,6 & 4,2 & 5,1 & 2,9 & & 9,7 & 6,3 & 2,4 & & & \\
\hline Fundidas de aço & 2,1 & 1,9 & 1,4 & 2,2 & 0,6 & & 4,1 & 4,4 & 6,0 & & & \\
\hline Fundidas de bronze & 0,4 & 0,4 & 0,3 & 0,5 & 6,6 & & 0,4 & 0,5 & 0,7 & & & \\
\hline Máquinas & 71,2 & 62,6 & 61,4 & 50,8 & 53,8 & 54,9 & 60,4 & 63,0 & 40,8 & 25,1 & 28,6 & 31,6 \\
\hline Moendas de cana & 27,7 & 21,8 & 19,8 & 19,8 & 22,9 & & 17,8 & 23,8 & 21,0 & & & \\
\hline Bombas & 2,3 & 2,0 & 2,5 & 4,9 & 2,7 & & 2,3 & 1,9 & 1,7 & & & \\
\hline Caldeiras & 13,2 & 12,1 & 12,6 & 10,0 & 14,2 & & 20,3 & 15,9 & 8,6 & & & \\
\hline Aparelhos para usinas & 27,9 & 26,8 & 26,6 & 16,1 & 14,0 & & 20,1 & 21,4 & 9,5 & & & \\
\hline Veículos & 0,0 & & & & & & & & & & & \\
\hline Departamentos (loja) & 8,4 & 10,7 & 9,4 & 17,2 & 9,1 & 8,3 & 5,1 & 4,3 & 7,8 & 4,8 & 5,8 & 5,8 \\
\hline Diversos & 13,4 & 20,8 & 23,3 & 24,1 & 27,1 & 25,6 & 20,4 & 21,6 & 42,2 & 62,9 & 58,1 & 54,5 \\
\hline Consertos & 0,8 & 0,5 & 0,6 & 1,0 & 1,8 & & 1,0 & 1,2 & 0,8 & & & \\
\hline Máquinas reformadas & 1,5 & 2,3 & 1,5 & 1,0 & 1,1 & & 1,1 & 1,5 & 6,7 & & & \\
\hline Mercadorias & 2,6 & 2,9 & 4,3 & 4,0 & 6,7 & & 2,6 & 2,4 & 2,1 & & & \\
\hline Materiais velhos & 0,7 & 0,4 & 0,7 & 0,8 & 0,3 & & 0,2 & 0,1 & 1,2 & & & \\
\hline Produtos diversos & 7,8 & 13,6 & 14,0 & 12,9 & 12,9 & & 11,5 & 13,9 & 13,4 & & & \\
\hline Pregos, porcas, parafusos & & 1,1 & 2,3 & 4,5 & 4,3 & & 2,2 & 0,4 & 1,6 & & & \\
\hline Tubos & & & & & 0,1 & & 0,0 & 0,0 & 0,0 & & & \\
\hline Válvulas & & & & & & & 1,8 & 1,5 & 0,8 & & & \\
\hline Produção própria & & & & & & & & 0,6 & 0,0 & & & \\
\hline Total & 100,0 & 100,0 & 100,0 & 100,0 & 100,0 & 100,0 & 100,0 & 100,0 & 100,0 & 100,0 & 100,0 & 100,0 \\
\hline
\end{tabular}

Fonte: São Paulo. Diário Oficial de São Paulo (vários anos), ver Tabela A.2, no Apêndice.

A maior mudança ocorreu na participação relativa de produtos diversos. O total das vendas da Dedini passou de 13,4\% em 1950 para 54,5\% em 1961. Houve uma pequena queda da participação relativa de produtos diversos entre 1955 e 1957. 
O Plano de Metas e a estrutura empresarial e financeira da indústria de máquinas e equipamentos...

A diversificação na produção foi uma estratégia adotada pela empresa para diminuir a dependência em relação à demanda do setor canavieiro. Assim, nos anos 1950 a empresa começou a produzir pregos, porcas e parafusos destinados às ferrovias de São Paulo e outros equipamentos por encomenda dos setores de cimento, mineração, papel, celulose e outros (Negri, 1977, p. 98).

Depois da análise econômico-financeira da Dedini nos anos 1950, nos concentraremos na análise da Romi, especialmente desde a sua transformação em sociedade anônima, em 1955, até 1961. Esses anos são importantes porque foi nesse período que se intensificou a instalação da indústria automobilística no país, expandindo, portanto, o mercado para as empresas que forneciam máquinas e equipamentos para o setor industrial.

Tabela 5

Análise econômico-financeira da Máquinas Agrícolas Romi S.A., 1955-1961

\begin{tabular}{c|c|c|c|c|c|c|c}
\hline Índices & 1955 & 1956 & 1957 & 1958 & 1959 & 1960 & 1961 \\
\hline Liquidez corrente & 1,57 & 1,60 & 1,80 & 1,62 & 1,91 & 1,68 & 1,43 \\
\hline Liquidez imediata & 0,08 & 0,05 & 0,10 & 0,09 & 0,28 & 0,22 & 0,09 \\
\hline Quociente cobertura total & 2,35 & 2,41 & 2,67 & 2,31 & 2,88 & 3,66 & 2,74 \\
\hline Imobilização do capital & 0,58 & 0,58 & 0,52 & 0,52 & 0,51 & 0,74 & 0,75 \\
\hline Rentabilidade do patrimônio líquido & 0,31 & 0,18 & 0,14 & 0,18 & 0,15 & 0,10 & 0,11 \\
\hline Rentabilidade sobre as vendas & 0,51 & 0,26 & 0,26 & 0,23 & 0,29 & 0,20 & 0,16 \\
\hline Rentabilidade do ativo & 0,18 & 0,11 & 0,09 & 0,10 & 0,10 & 0,07 & 0,07 \\
\hline & & & & & & & \\
\hline Participação capital de terceiros & 0,74 & 0,71 & 0,60 & 0,76 & 0,53 & 0,38 & 0,57 \\
\hline \% capital de terceiros no ativo & 42,58 & 41,44 & 37,44 & 43,33 & 34,68 & 27,29 & 36,44 \\
\hline$\%$ capital próprio no ativo & 57,42 & 58,56 & 62,56 & 56,67 & 65,32 & 72,71 & 63,56 \\
\hline
\end{tabular}

Fonte: São Paulo. Diário Oficial de São Paulo (vários anos), ver Tabela A.3, no Apêndice.

Os indicadores de liquidez da Romi permaneceram relativamente estáveis ao longo da segunda metade dos anos 1950, com uma significativa melhora no índice de liquidez corrente e imediata entre os anos 1958 e 1960. O quociente de cobertura total, que mede a capacidade da empresa em liquidar suas dívidas, também melhorou entre os anos 1959 e 1961. A imobilização do capital aumentou nos anos 1960 e 1961, mostrando que a evolução do setor exigiu maior quantidade de capital para a modernização. A evolução do ativo total da empresa foi com aumento de capital próprio, diminuindo a participação de capital de terceiros no ativo total da empresa entre 1955 e início dos anos 1960 (com exceção dos anos de 1958 e 1961, em que houve aumento da participação de terceiros). 
Os indicadores de rentabilidade (do patrimônio líquido, sobre vendas e do ativo) da Romi diminuíram na segunda metade dos anos 1950. De uma rentabilidade do patrimônio líquido de $31 \%$ em 1955 passou para 11\% em 1961. Essa queda da rentabilidade possivelmente é explicada pelo aumento da concorrência no mercado ${ }^{22}$, já que as vendas (receitas totais) da Romi continuaram a crescer entre 1955 e 1961 (mais do que dobraram em valor, ver Tabela 7). Houve, portanto, necessidade de modernização da empresa no final dos anos 1950 devido ao aumento da concorrência (interna e externa) e aumento da demanda da indústria automobilística. Assim, a Romi adaptou-se ao mercado e continuou sendo a principal empresa produtora de tornos no Brasil nos anos 1960, uma das maiores do mundo.

As Tabelas 6 e 7 resumem os principais indicadores para a análise da evolução no período da Dedini e da Romi, respetivamente.

Tabela 6

Evolução do ativo total, capital social, lucros e receitas totais da M. Dedini S.A.

- Metalúrgica, 1950-1961, em cruzeiros a preços constantes de 1961

\begin{tabular}{c|c|c|c|c}
\hline & \multicolumn{4}{|c}{ Dedini em Cr\$ a preços constantes de 1961 } \\
\hline Anos & Ativo total & Capital Social & Lucros & Receitas Totais \\
\hline 1950 & 689.969 .147 & 56.783 .603 & 127.655 .715 & 839.219 .206 \\
\hline 1951 & 911.851 .176 & 238.984 .738 & 163.642 .304 & 1.102 .192 .058 \\
\hline 1952 & 1.422 .903 .386 & 444.629 .630 & 325.433 .797 & 1.396 .504 .499 \\
\hline 1953 & 1.646 .597 .451 & 577.780 .749 & 109.906 .281 & 1.144 .852 .716 \\
\hline 1954 & 1.445 .389 .652 & 439.207 .317 & 107.103 .887 & 996.278 .452 \\
\hline 1955 & 1.378 .823 .898 & 775.906 .643 & 92.139 .579 & 966.811 .281 \\
\hline 1956 & 1.213 .761 .973 & 623.636 .364 & 108.730 .283 & 895.972 .009 \\
\hline 1957 & 1.171 .275 .596 & 530.933 .661 & 79.395 .231 & 1.100 .646 .729 \\
\hline 1958 & 1.463 .724 .433 & 590.161 .765 & 79.880 .665 & 1.490 .217 .934 \\
\hline 1959 & 1.248 .330 .182 & 411.298 .682 & 175.492 .075 & 2.127 .389 .779 \\
\hline 1960 & 1.534 .983 .891 & 333.432 .641 & 122.406 .870 & 1.873 .859 .307 \\
\hline 1961 & 1.536 .605 .021 & 384.000 .000 & 133.352 .215 & 2.048 .653 .451 \\
\hline
\end{tabular}

Nota: Os valores da Tabela 1 e Quadro A.1 foram deflacionados pelo índice de preços de produtos industriais de Malan et al. (1977, p. 516).

Fonte: Tabela 1 e Quadro A.1, no Apêndice.

É possível perceber que houve crescimento das receitas totais tanto da Dedini (o valor real das receitas totais mais que dobra entre 1956 e 1961, ver Tabela 6) quanto da Romi (dobra entre 1955 e 1961, ver Tabela 7). A Instrução 70 da Sumoc (1953) e depois a Lei 3244 (1957) promoveram uma proteção contra as importações

(22) Havia 24 empresas produzindo tornos, o principal produto da Romi, no Brasil em 1961 (Cepal, 1962, p. 30). Outro estudo apresenta um quadro com 30 empresas produzindo tornos entre 1958 e 1962 (Banas, 1962, p. 137). 
O Plano de Metas e a estrutura empresarial e financeira da indústria de máquinas e equipamentos...

com a depreciação implícita da taxa de câmbio conforme observamos na seção anterior. Possivelmente as empresas nacionais aproveitaram para expandir suas vendas (receitas totais) diante da proteção implícita ao mercado interno. No caso da Romi, a implantação da indústria automobilística e demais investimentos em infraestrutura do Plano de Metas podem ter potencializado a demanda por seus produtos.

A Dedini parece ter tido sua expansão afetada pela mudança no mercado de máquinas para o setor canavieiro entre 1952 e 1953.

Tabela 7

Evolução do ativo total, capital social, lucros e receitas totais da Máquinas Agrícolas

Romi S.A., 1955-1961, em cruzeiros a preços constantes de 1961

\begin{tabular}{c|c|c|c|c}
\hline Anos & Ativo total & Capital Social & Lucros & Receitas Totais \\
\hline 1955 & 938.652 .733 & 258.635 .548 & 164.802 .230 & 324.709 .974 \\
\hline 1956 & 1.041 .052 .139 & 472.924 .242 & 111.454 .798 & 429.543 .578 \\
\hline 1957 & 1.051 .924 .787 & 442.444 .717 & 94.459 .277 & 368.956 .229 \\
\hline 1958 & 1.224 .814 .764 & 378.308 .824 & 121.852 .283 & 532.407 .192 \\
\hline 1959 & 1.037 .926 .935 & 351.537 .335 & 101.496 .274 & 347.819 .341 \\
\hline 1960 & 1.740 .925 .288 & 284.985 .163 & 129.304 .139 & 654.998 .350 \\
\hline 1961 & 1.578 .820 .578 & 610.000 .000 & 114.918 .323 & 701.881 .427 \\
\hline
\end{tabular}

Nota: Os valores da Tabela 2 e A.3 foram deflacionados pelo índice de preços de produtos industriais de Malan et al. (1977, p. 516).

Fonte: Tabela 2 e Tabela A.3, no Apêndice.

Os lucros permanecem praticamente constantes tanto para a Dedini como para a Romi entre 1956 e 1961 (ver Tabelas 6 e 7). No caso da Romi, a entrada de empresas estrangeiras (pela Instrução 113 da Sumoc de 1955) pode ter aumentando a concorrência no setor de máquinas-ferramentas, diminuindo a margem de lucro da empresa nacional $^{23}$. A Romi teve seu ativo aumentado em 52\% entre 1956 e 1961 em um esforço de adaptação e expansão da sua capacidade de produção. No caso da Dedini, as explicações para a evolução da rentabilidade da empresa parecem estar mais próximas da evolução do setor canavieiro do que do Plano de Metas.

\section{Conclusões}

Depois de examinar a evolução das políticas econômicas ao longo dos anos 1950 e apresentar os estudos de casos de empresas produtoras de máquinas e equipamentos nacionais, serão resumidas as principais conclusões do artigo.

(23) Outra explicação para a diminuição da lucratividade é o aumento das despesas, decorrente das mudanças nas necessidades da estrutura industrial do setor. 
A Instrução 70 da Sumoc (1953) e a Lei 3244 (1957) promoveram proteção contra as importações com a depreciação implícita da taxa de câmbio e tarifas alfandegárias que, possivelmente, estimularam a indústria de máquinas e equipamentos no Brasil. Essa proteção parece ter criado as condições necessárias para a expansão dos investimentos, com o aumento do capital social da Dedini, principalmente entre 1951 e 1955, e da Romi, principalmente entre 1953 e 1956 . No caso da Romi, a implantação da indústria automobilística ${ }^{24}$ e demais investimentos em infraestrutura do Plano de Metas podem ter potencializado a demanda por seus produtos, principalmente os tornos, já que a empresa apresentou indicadores positivos de vendas na segunda metade dos anos 1950. A Dedini parece ter tido sua expansão afetada pela mudança no mercado de máquinas para o setor canavieiro entre 1952 e 1953.

A Instrução 113 da Sumoc (1955) promoveu o aumento do capital estrangeiro no país. Os efeitos podem ter sido o aumento da concorrência de empresas estrangeiras com as empresas nacionais, assim como a ampliação da associação com essas empresas. $\mathrm{O}$ aumento da concorrência pode explicar a queda da rentabilidade da Romi, produtora de máquinas-ferramentas. No entanto, também explica a expansão do seu investimento (capital social e ativo total) com a aquisição de máquinas do exterior em 1957, 1959 e 1961. Assim, há indícios de que as políticas do período impactaram positivamente no investimento e negativamente na rentabilidade dessas empresas nacionais de máquinas e equipamentos.

Com relação aos demais estímulos governamentais, os empresários do setor de máquinas e equipamentos do país apresentavam grande quantidade de reclamações sobre o financiamento público de longo prazo. O BNDE, que nos anos 1950 atuou quase que exclusivamente em setores de base, estabeleceu normas de financiamento para a fabricação, compra e venda de máquinas e equipamentos apenas no início de $1962^{25}$ (Banas, 1962, p 7-9).

\section{Referências bibliográficas}

ALMEIDA, F. L. de. A expansão da indústria de bens de capital: fatores determinantes. Rio de Janeiro: Instituto de Documentação / Editora da Fundação Getúlio Vargas, 1983.

(24) É interessante assinalar que as próprias diretrizes de política governamental inviabilizaram a produção do automóvel nacional fabricado pela Romi, com capacidade para três passageiros, o Romi-Isetta entre 1957 e 1961. Os veículos com capacidade inferior a quatro passageiros tinham sido excluídos dos benefícios fiscais, cambiais e financeiros concedidos pelo governo às montadoras estrangeiras. Essas montadoras adquiriram divisas estrangeiras para a importação de equipamentos a taxa de 40 cruzeiros por dólar. A Romi tinha que pagar entre 230 a 250 cruzeiros por dólar nos leilões de moeda. A importação dos 18\% de componentes para o Romi-Isetta saía mais cara do que os 60-70\% de componentes importados dos automóveis das demais montadoras, inviabilizando a sua produção (Brandão, 2008, p. 97-98).

(25) Com a Resolução 88 de 12 de janeiro de 1962 do BNDE. 
ARAÚJO, V. L. de et al. La experiencia brasilena com bancos de desarrollo: el caso del Banco Nacional de Desarrollo Económico y Social de Brasil. In: ROUGIER, M. (Comp.). La banca de desarrollo en América Latina: luces y sombras en la industrialización de la región. Buenos Aires: Fondo de Cultura Económica, 2011.

BANAS, G. Anuário Banas: a indústria de máquinas. São Paulo. Editora Banas, 1962.

BASTOS, P. P. Z. Ascensão e crise do projeto nacional-desenvolvimentista de Getúlio Vargas. In: BASTOS, P. P. Z.; FONSECA, P. C. D. (Org.). A Era Vargas: desenvolvimentismo, economia e sociedade. São Paulo: Editora Unesp, 2012.

BERGSMAN, J. BRAZIL - Industrialization and Trade Policies. London: Oxford University Press, 1970.

BRANDÃO, I. de L. Oficina de sonhos: Américo Emílio Romi, aventuras de um pioneiro. São Paulo: Editora DBA, 2008.

BRASIL. Programa de Metas del presidente Juscelino Kubitschek. Situación del plan de fomento económico el 31 de diciembre del 1958. Presidencia de la República. Servicio de Documentación. Rio de Janeiro, 1959.

CAPUTO, A. C.; MELO, H. P. de. A industrialização brasileira nos anos de 1950: uma análise da Instrução 113 da Sumoc. Estudos Econômicos, v. 29, n. 3, jul./set. 2009.

CEPAL. La fabricación de maquinarias y equipos industriales em América Latina. II. Las máquinas-herramientas en el Brasil. Nueva York: Naciones Unidas, 1962.

CUNNINGHAM, S. M. Brazilian private industrial enterprise, 1950-1980. University of London. Institute of Latin American Studies, Jul. 1982. (Working Papers).

DOELLINGER, C. V. et al. Política e estrutura das importações brasileiras. Rio de Janeiro: Ipea, 1977.

ERBER, F. S. et al. Absorção e criação de tecnologia na indústria de bens de capital. Rio de Janeiro: Finep, 1974.

FISHLOW, A. Origens e consequências da substituição de importações no Brasil. Estudos Econômicos, São Paulo, v. 2, n. 6, dez. 1972.

HABER, S. The political economy of industrialization. In: BULMER-THOMAS, V.; COATSWORTH, J. H.; CONDE, R. C. The Cambridge economic history of Latin America. New York: Cambridge University Press, 2008. v. II.

LAFER, C. JK e o programa de metas (1956-61): processo de planejamento e sistema político no Brasil. Rio de Janeiro: Editora FGV, 2002. 
LAGO, L. A. C. et al. A indústria brasileira de bens de capital: origens, situação recente e perspectivas. $1^{\text {a }}$ ed. Rio de Janeiro: FGV/IBRE, 1979.

LEFF, N. H. The Brazilian capital goods industry, 1929-1964. Cambridge, Mass.: Harvard University Press, 1968.

LESSA, C. Quinze anos de política econômica. São Paulo: Brasiliense, 1982.

MALAN, P. et al. Política econômica externa e industrialização no Brasil (1939/52). Rio de Janeiro: IPEA/INPES, 1977.

NEGRI, B. Um estudo de caso da indústria nacional de equipamentos: análise do grupo Dedini (1920- 1975). 1977. Dissertação (Mestrado)-Instituto de Economia da Unicamp, Campinas, 1977.

ORENSTEIN, L; SOCHACZEWSKI, A. C. Democracia com desenvolvimento: 1956-1961. In: ABREU, Marcelo de Paiva. A ordem do progresso: cem anos de política econômica republicana 1889-1989. Rio de Janeiro: Campus, 1990.

SÃO PAULO. Diário Oficial do Estado de São Paulo. Vários anos.

SÃO PAULO. Junta Comercial de São Paulo. Arquivos.

SERRA, J. Ciclos e mudanças estruturais na economia brasileira do após-guerra. Revista de Economia Política, v. 2/2, n. 6, abr./jun. 1982.

SINGER, P. Interpretação do Brasil: uma experiência histórica de desenvolvimento. In: PIERUCCI, A. F. de O. et al. História geral da civilização brasileira. 4. ed. Rio de Janeiro: Bertrand Brasil, 2007. t. 3. v. 11. Introdução geral de Sérgio Buarque de Holanda.

TAVARES, M. C. Ciclo e crise: o movimento recente da industrialização brasileira. Campinas: Unicamp, 1998.

VIANNA, S. B. Duas tentativas de estabilização: 1951-1954. In: ABREU, Marcelo de Paiva. A ordem do progresso: cem anos de política econômica republicana 18891989. Rio de Janeiro: Campus, 1990. 
O Plano de Metas e a estrutura empresarial e financeira da indústria de máquinas e equipamentos...

\section{Apêndice}

Quadro A.1

Registros da Romi arquivados na Junta Comercial, Estado de São Paulo, 1938-1962

\begin{tabular}{|c|c|c|}
\hline Número & Data & Observação \\
\hline 51.368 & $15 / 06 / 1938$ & $\begin{array}{c}\text { Contrato social da firma Machinas Agricolas Romi Ltda. Sócios } \\
\text { Emílio Romi (200:000\$000), Oscar Berggren (50:000\$000) de } \\
\text { Americana, Carlos Chiti (50:000\$000). }\end{array}$ \\
\hline 52.196 & 09/12/1938 & $\begin{array}{l}\text { Retira-se Oscar Berggren, transferindo sua quota de capital ao } \\
\text { sócio Emílio Romi. }\end{array}$ \\
\hline 61.969 & $24 / 02 / 1942$ & $\begin{array}{l}\text { Retira-se Carlos Chiti. É admitido Placido Ribeiro Ferreira com } \\
\text { capital de 50:000\$000, de Santa Bárbara. }\end{array}$ \\
\hline 66.684 & 02/04/1943 & $\begin{array}{c}\text { Capital elevado de Cr\$300000,00 para Cr\$1500000,00. Divido } \\
\text { em } 4 \text { partes: a) Emílio Romi Cr\$ } 1200000,00, \text { b) Baptista Riceti } \\
\text { Cr\$ 150000,00, de São Carlos, c) Placido Ribeiro Ferreira Cr\$ } \\
\text { 100.000,00, d) Alfredo Fonseca Braga Cr\$ 50.000,00 de Santa } \\
\text { Bárbara. }\end{array}$ \\
\hline 67.796 & $02 / 07 / 1943$ & $\begin{array}{l}\text { Retira-se Placido Ribeiro Ferreira, transferindo seu capital de Cr\$ } \\
\qquad 100000,00 \text { a Emílio Romi. }\end{array}$ \\
\hline 78.983 & $27 / 04 / 1945$ & $\begin{array}{l}\text { Retira-se Alfredo Fonseca Braga, transferindo suas cotas no valor } \\
\text { de Cr\$50000,00 ao sócio Emílio Romi. }\end{array}$ \\
\hline 89.171 & 09/08/1946 & $\begin{array}{c}\text { Capital elevado para Cr\$2350000,00 Emílio Romi Cr\$ } \\
\text { 1350000,00; Baptista Ricetti Cr\$150000,00 e Alvares Romi, } \\
\text { admitido 850000,00 (26/06/1946) }\end{array}$ \\
\hline 89.172 & 09/08/1946 & $\begin{array}{l}\text { O sócio Baptista Lauria Ricetti transfere suas quotas no total de } \\
\text { Cr\$150000,00 a Alvares Romi }\end{array}$ \\
\hline 90.617 & 08/10/1946 & $\begin{array}{l}\text { Capital elevado para Cr\$5000000,00: Emílio Romi 1750000,00; } \\
\text { Alvares Romi 1000000,00 e os sócios admitidos Carlos Chiti } \\
\text { Cr\$1250000,00; Romeu Romi e Julieta Romi Cr\$500000,00 cada } \\
\text { um. }\end{array}$ \\
\hline 92.657 & $10 / 01 / 1947$ & $\begin{array}{l}\text { Capital elevado para Cr\$ 6000000,00: Emílio Romi Cr\$ } \\
\text { 1750000,00; Alvares Romi Cr\$ 1000000,00; Julieta Romi e Romeu } \\
\text { Romi Cr\$ 500000,00 cada; Carlos Chiti Cr\$ 1250000,00; Giordano } \\
\text { Romi Cr\$ 1000000,00. }\end{array}$ \\
\hline 96.487 & 06/06/1947 & $\begin{array}{c}\text { Capital elevado para Cr\$ 9000000,00: Emilio Romi Cr\$ } \\
\text { 2600000,00; Carlos Chiti Cr\$ 1800000,00; Alvares Romi Cr\$ } \\
\text { 1500000,00; Giordano Romi Cr\$ 1500000,00; Romeu Romi Cr\$ } \\
\text { 800000,00; Julieta Romi Cr\$ 800000,00. }\end{array}$ \\
\hline 103.443 & $16 / 04 / 1948$ & $\begin{array}{c}\text { Capital elevado para Cr\$ 10000000,00: Emilio Romi Cr\$ } \\
\text { 2890000,00; Carlos Chiti Cr\$ 2000000,00; Alvares Romi e } \\
\text { Giordano Romi Cr\$ 1665000,00 cada um; Romeu Romi e Julieta } \\
\text { Romi Cr\$ 890000,00 cada um. Objeto: fabricação de máquinas em } \\
\text { geral e congêneres. }\end{array}$ \\
\hline 156.931 & 28/07/1953 & $\begin{array}{l}\text { Capital elevado para Cr\$ 22000000,00: Emilio Romi Cr\$ } \\
\text { 6358000,00; Carlos Chiti Cr\$ 4400000,00; Giordano Romi Cr\$ } \\
\text { 3663000,00; Alvares Romi Cr\$ 3663000,00; Julieta Romi Zanaga } \\
\text { Cr\$ 1958000,00; Romeu Romi Cr\$ 1958000,00. }\end{array}$ \\
\hline
\end{tabular}

Continua... 


\begin{tabular}{|c|c|c|}
\hline Número & Data & Observação \\
\hline 166.231 & $27 / 04 / 1954$ & $\begin{array}{l}\text { Capital elevado para Cr\$40000000,00. Incorporação de um terreno } \\
(\mathrm{Cr} \$ 18000000,00) \text { de Emílio Romi à sociedade. }\end{array}$ \\
\hline 90.431 & 23/11/1954 & $\begin{array}{l}\text { Aumento de capital para Cr\$ } 45000000,00 \text { e alteração de sociedade } \\
\text { por quotas de responsabilidade limitada "Máquinas Agrícolas } \\
\text { Romi Ltda." para Sociedade Anônima "Máquinas Agrícolas Romi } \\
\text { S.A.". Admitem como sócios Flora Sans Romi e Maria Conceição } \\
\text { Pimentel Romi com Cr\$ 500000,00 cada. Outros sócios aumentam } \\
\text { o capital (ver p.124). }\end{array}$ \\
\hline 91.224 & $24 / 12 / 1954$ & Publicação doc. Constituição D.O.E. de 07/12/1954 \\
\hline 95.036 & $13 / 05 / 1955$ & Ata ordinária de $04 / 04 / 1955$ \\
\hline 97.883 & 08/07/1955 & $\begin{array}{l}\text { Ata extraordinária de } 21 / 05 / 1955 \text { subscrição ações da Premier Imp. } \\
\text { e Exportadora valor de Cr\$ } 2445000,00 \text {. }\end{array}$ \\
\hline 100.931 & $18 / 11 / 1955$ & $\begin{array}{l}\text { Ata extraordinária de 08/11/1955. Aprovação proposta de aumento } \\
\text { de capital para Cr\$60000000,00. Incorporação de terrenos }(\mathrm{Cr} \$ \\
15000000,00) \text { de Emilio Romi na sociedade. }\end{array}$ \\
\hline 101.338 & $09 / 12 / 1955$ & Ata extraordinária de 15/09/1955. Alteração do art. 5. do estatuto. \\
\hline 101.519 & 20/12/1955 & $\begin{array}{l}\text { Ata extraordinária de 23/11/1955. Capital elevado para } \mathrm{Cr} \$ \\
60000000,00 \text {. }\end{array}$ \\
\hline 104.182 & $13 / 04 / 1956$ & Publicação de balanço de 1955 no D.O.E. de 05/04/1956. \\
\hline 105.502 & $08 / 05 / 1956$ & Ata ordinária de 12/04/1956. \\
\hline 112.753 & $13 / 11 / 1956$ & $\begin{array}{l}\text { Ata extraordinária de 01/10/1956. Capital elevado para Cr\$ } \\
136500000,00 \text {. }\end{array}$ \\
\hline 118.591 & 08/05/1957 & Publicação do balanço de 1956 no D.O.E. de 02/04/1957. \\
\hline 119.826 & 29/05/1957 & Ata Ordinária de 02/04/1957. \\
\hline 126.063 & 23/10/1957 & $\begin{array}{l}\text { Ata Extraordinária de 07/10/1957. Aprova proposta de aumento de } \\
\text { capital para Cr\$150000000,00. Manifestação de interesse de } \\
\text { pessoas e empresas dos EUA em participar da sociedade. }\end{array}$ \\
\hline 126.674 & $16 / 11 / 1957$ & Publicada ata ordinária de 07/10/1957 no D.O.E. de 1/11/1957. \\
\hline 127.371 & $18 / 12 / 1957$ & $\begin{array}{l}\text { Ata Extra de 11/11/1957. Nomeação de peritos para avaliarem os } \\
\text { bens a integralizar o aumento. Capital elevado para Cr\$ } \\
\text { 150000000,00. Aumento de Cr\$3500000,00 (por Américo Romi) e } \\
\text { Cr\$10000000,00 (capital integralizado com as seguintes máquinas: } \\
\text { compressor de ar Chicago Pneumatic, retificadora Jones \& } \\
\text { Lamson, máquinas para cortar engrenagens Gleason) João } \\
\text { Mammana D'Agostinho, brasileiro, com escritório de representação } \\
\text { em Nova York. }\end{array}$ \\
\hline 127.742 & 08/01/1957 & Publicação da ata extra de 11/11/1957 no D.O.E. de 3/01/1958. \\
\hline 133.400 & $19 / 06 / 1958$ & Ata Ordinária de 07/04/1958. Eleição da diretoria. \\
\hline 144.998 & $15 / 05 / 1959$ & $\begin{array}{c}\text { Ata ordinária de 10/04/1959. Diretor Presidente Olimpia Gelli } \\
\text { Romi. }\end{array}$ \\
\hline 153.668 & 09/10/1959 & $\begin{array}{c}\text { Ata extra de 04/08/1959. Novos estatutos. Capital Cr\$ } \\
\text { 200000000,00. Necessidade de aquisição de máquinas especiais } \\
\text { (integralizado com máquinas Cr\$50000000,00 por João Mammana } \\
\text { Dagostinho). }\end{array}$ \\
\hline
\end{tabular}


O Plano de Metas e a estrutura empresarial e financeira da indústria de máquinas e equipamentos...

\begin{tabular}{|c|c|c|}
\hline Número & Data & Observação \\
\hline 161.963 & $03 / 06 / 1960$ & Ata ordinária de 08/04/1960. \\
\hline 175.603 & $10 / 02 / 1961$ & $\begin{array}{c}\text { Ata extra de 20/12/1960. Elevação do capital para Cr\$ } \\
610000000,00 . \text { Investimento da firma Eartern Machinery Company } \\
\text { (Cincinati, Ohio). }\end{array}$ \\
\hline 178.134 & $18 / 04 / 1961$ & Ata ordinária de 03/04/1961. \\
\hline 200.943 & $15 / 05 / 1962$ & Ata ordinária de 02/04/1962. \\
\hline 206.572 & $03 / 07 / 1962$ & $\begin{array}{c}\text { Ata extra de 10/05/1962 para elevação de capital para Cr\$ } \\
703600000,00 \text { - mudança de denominação social para "Indústrias } \\
\text { Romi S/A". }\end{array}$ \\
\hline
\end{tabular}

Fonte: São Paulo. Junta Comercial de São Paulo.

Tabela A.1

Balanço patrimonial e demonstração da conta lucros e perdas da M. Dedini S.A., 1950-1961

\begin{tabular}{|c|c|c|c|c|c|c|c|c|c|c|c|c|}
\hline & 1950 & 1951 & 1952 & 1953 & 1954 & 1955 & 1956 & 1957 & 1958 & 1959 & 1960 & 1961 \\
\hline Ativo Circulante & 52.485 .040 & 90.481 .035 & 166.716 .6212 & 232.806 .2252 & 271.598 .098 & 291.303 .588 & 289.311 .125 & 327.400 .258 & 460.765 .607 & 565.660 .430 & \multirow{2}{*}{\multicolumn{2}{|c|}{840.878 .497 1.275.539.368 }} \\
\hline Disponível (Caixas e Bancos) & 7.630 .329 & 12.986 .934 & 5.501 .855 & 4.455 .044 & 5.179 .088 & 11.450 .434 & 701.759 & 1.712 .778 & 14.945 .083 & 36.800 .152 & 16.555 .633 & \\
\hline Realizável & 44.518 .752 & 73.638 .628 & 135.403 .674 & 177.011 .083 & 185.970 .644 & 219.688 .189 & 231.708 .114 & 267.143 .930 & 362.429 .043 & 436.458 .869 & 575.196 .904 & 860.792 .681 \\
\hline Contas de Compensação & 295.972 & 1.095.972 & 25.142 .257 & 47.939 .671 & 60.747 .440 & 49.742 .985 & 46.276 .033 & 52.206 .150 & 72.001 .537 & 78.034 .324 & 249.125 .960 & 388.617 .369 \\
\hline Circulante (Importação em trâ & 39.986 & 2.759 .501 & 668.836 & 3.400 .427 & 19.700 .926 & 10.421 .980 & 10.625.220 & 6.337 .401 & 11.389 .944 & 14.367.085 & & \\
\hline Ativo Permanente & 20.420 .072 & 23.984.581 & 25.295 .331 & 23.681 .674 & 24.583 .372 & 28.565 .179 & 61.016 .675 & 69.691 .926 & 119.603 .265 & 144.551.577 & 236.359 .261 & 261.065 .653 \\
\hline Imobilizado & 20.101 .191 & 21.432 .435 & 24.821 .617 & 23.577 .237 & 24.361 .563 & 28.455 .235 & 54.490 .546 & 66.025 .841 & 119.109 .154 & 144.551 .577 & 207.505 .053 & 248.287.922 \\
\hline Outras Contas & 318.881 & 2.552 .146 & 473.714 & 104.438 & 221.809 & 109.944 & 331.326 & 48.849 & 494.111 & & & \\
\hline Resultados pendentes & & & & & & & 6.194 .803 & 3.617 .236 & & & 28.854 .208 & 12.777 .731 \\
\hline Ativo Total & 72.905 .112 & 114.465 .616 & 192.011 .952 & 256.487 .9002 & 296.181 .470 & 319.868 .768 & 350.327 .800 & 397.092 .185 & 580.368 .872 & 710.212 .007 & 1.077.237.758 1 & 1.536 .605 .021 \\
\hline Passivo Circulante & 7.578.978 & 27.933.130 & 59.143 .898 & 108.481 .5171 & 135.891 .796 & 135.740 .033 & 126.357 .542 & 143.952 .214 & 238.444.257 & 235.263.685 & 616.327.877 & 893.565 .413 \\
\hline Exigivel (Contas Bancárias, $\mathrm{Fr}$ & $=7.283 .006$ & 26.837 .158 & 26.859 .474 & 53.391 .643 & 53.946 .827 & 51.811 .002 & 52.169 .402 & 69.487 .466 & 114.364 .194 & 141.561 .147 & 312.751 .470 & 424.600 .158 \\
\hline Contas de Compensação & 295.972 & 1.095 .972 & 25.142 .257 & 47.939 .671 & 60.747 .440 & 49.742 .985 & 46.276 .033 & 52.206 .151 & 72.001 .537 & 78.034 .324 & 249.125 .960 & 388.617 .369 \\
\hline Resultado Pendente (receitas a & a realizar) & & 7.071 .025 & 7.150 .202 & 1.197 .529 & 8.111 .504 & 9.481 .340 & 6.641 .360 & 29.908 .388 & 15.668 .214 & 54.450 .447 & 80.347 .886 \\
\hline Outras Contas & & & 71.141 & & 20.000 .000 & 1.074 .542 & 6.430 .768 & 3.617 .236 & 170.138 & & & \\
\hline Provisōes & & & & & & 25.000 .000 & 12.000 .000 & 12.000 .000 & 22.000 .000 & & & \\
\hline Patrimônio Líquido & 65.326 .113 & 86.532 .486 & 132.868 .035 & 148.006 .3821 & 160.289 .674 & 184.128 .735 & 223.970 .258 & 253.139.971 & 341.924.579 & 474.948.325 & 460.909 .972 & 643.030 .610 \\
\hline Capital, Reservas e Lucros su & 65.326 .113 & 86.532 .486 & 132.868 .035 & 148.006 .382 & 160.289 .674 & 184.128 .735 & 223.970 .258 & 253.139 .971 & 341.924 .579 & 474.948 .325 & 460.909 .972 & 643.030 .610 \\
\hline Passivo Total 7 & 72.905 .091 & 114.465 .616 & 192.011 .932 & 256.487 .8992 & 296.181 .470 & 319.868 .767 & 350.327 .800 & 397.092 .185 & 580.368 .836 & 710.212 .010 & 1.077.237.8491 & 1.536 .596 .023 \\
\hline \multicolumn{13}{|c|}{ ta Lucros e Perdas da M. Dedini S.A. - Metalúrgica (em $\left.C_{r} \$\right)$} \\
\hline & 1950 & 1951 & 1952 & 1953 & 1954 & 1955 & 1956 & 1957 & 1958 & 1959 & 1960 & 1961 \\
\hline \multicolumn{13}{|l|}{ Crédito (Vendas) } \\
\hline a) peças (peças fundic & 6.168 .175 & 12.358 & 1.080 .188 & 13.562 .769 & 20.089 .597 & 23.053.296 & 34.027 .448 & 39.700 .458 & 52.177 .475 & 84.237 .620 & 95.651 .805 & 161.081 .491 \\
\hline ndas, bomba & a 62.465 .998 & 85.657 .905 & 114.547 .754 & 88.257 .461 & 107.417 .928 & 114.072 .206 & 144.743 .885 & 224.593 .281 & 234.433 .329 & 292.871 .584 & 366.852 .214 & 631.380 .958 \\
\hline c) veíc & 1.800 & & & & & & & & & & & \\
\hline d) & 7.399 .558 & 614.928 & 17.471 .209 & 29.954.311 & 18.120 .968 & 290.683 & 12.151 .580 & 15.229 .479 & 44.989 .631 & 56.518 .752 & 73.698 .763 & 115.214 .342 \\
\hline e) diversos (consertos, reform & 11.754 .847 & 28.479 .187 & 43.497 .261 & 41.947.416 & 54.181 .374 & 53.201 .335 & 48.782 .083 & 76.835 .692 & 242.376 .706 & 734.494 .511 & 744.892 .194 & 1.088 .377 .183 \\
\hline Receita Extraord & $\quad 885.139$ & 1.080 .814 & 1.853 .175 & 4.609.952 & 4.340 .279 & 4.954.901 & 6.201 .276 & 5.352 .352 & 4.979 .441 & 7.381 .952 & 10.976 .091 & 16.447 .194 \\
\hline & & 514.112 & & & 1.874 & 11.714 .913 & 1.179 .938 & & & & & 5.301 \\
\hline Provisōes & & & & & & & 11.517 .955 & 11.435 .943 & 10.768 .940 & 20.642 .697 & 22.986 .381 & 34.796 .982 \\
\hline Crédito Total & 88.675 .515 & 138.359 .303 & 188.449 .587 & 178.331 .9102 & 204.152.019 & 224.287.332 & 258.604 .166 & 373.147.204 & 590.873 .583 & 1.210 .335 .043 & 1.315 .057 .4482 & 2.048.653.451 \\
\hline \multicolumn{13}{|l|}{ Débito } \\
\hline Despesa com le & 1.936 .918 & 342.017 & 523.058 & 060.602 & 2.986 .067 & 4.010 .056 & 7.568 .756 & 12.133 .867 & 15.432 .969 & 29.542 .529 & 41.556 .270 & 77.832 .071 \\
\hline Despesas diretas da fabricaçă & 59.126 .297 & 94.206 .038 & 113.426 .520 & 110.903 .977 & 114.252 .845 & 130.470 .308 & 138.354.004 & 245.537 .771 & 413.547 .603 & 837.153 .844 & 858.592 .307 & 1.375 .856 .642 \\
\hline $\begin{array}{ll}\mathrm{De} \\
\text { a) }\end{array}$ & 246.703 & & & & & & & & & & & \\
\hline & & & & & & & & & & & & 3.420 .481 \\
\hline & 1.083 .660 & & & & & & & & & & & 29.770 .581 \\
\hline d) juros e comissōes & 2.423 .563 & 4.842 .364 & 6.754 .144 & 8.483 .948 & 10.570 .167 & 12.158 .177 & 10.149 .237 & 16.417 .587 & & .589 & 51.411 .313 & 78.051 .786 \\
\hline e) transporte & 240.036 & & & 105.567 & 258.026 & 153.132 & & 11.776 .323 & .298 & 734 & & 95.955.968 \\
\hline f) $i m_{1}$ & 5.003 .223 & & 9.663 & 15.915 & & & & & & & 8.650 & 35.199 .920 \\
\hline g) $\mathrm{co}$ & 927.371 & & & 1.341 .713 & 2.656 & 52.639 & & & & & & 22.461 .992 \\
\hline is e lubrificantes & & & & & & & & & & & & \\
\hline & 1.446 .675 & 1.845 .040 & 2.071 .082 & 2.281 .583 & 2.504 .090 & 2.439 .066 & 2.573 .086 & 3.884 .313 & 5.458 .451 & 10.596 .487 & 12.190 .504 & 16.047 .818 \\
\hline & 590.897 & 845.788 & 1.335 .035 & & 1.699 .788 & 3.023.082 & 3.402 .379 & 3.381 .325 & 6.019 .710 & 8.377 .524 & 27.099.275 & 25.216 .467 \\
\hline Lucros e Per & 24.351 & & & 7.359 .354 & 1.474 .629 & & & & & & & \\
\hline Provisōes & & & & & 20.000 .000 & 23.000 .000 & 12.000 .000 & 12.000 .000 & 22.000 .000 & 26.000 .000 & 36.000 .000 & 40.000 .000 \\
\hline & & & & & & & & & & & & \\
\hline Lucro Liquido da & 13.488 .653 & 20.542 .187 & 43.915 .265 & 17.119 .929 & 21.947 .152 & 21.375 .154 & 31.382 .793 & 26.917 .001 & 31.672 .800 & 99.842 .638 & 4.030 & 133.3 \\
\hline Débito Total & 88.670 .516 & 138.369 .253 & 188.449.577 & 178.331 .9102 & 204.152 .020 & 224.287 .390 & 258.604 .167 & 373.147 .703 & 590.873 .578 & 1.210 .335 .040 & 1.315 .056 .9452 & 2.048 .653 .447 \\
\hline
\end{tabular}

Fonte: São Paulo. Diário Oficial de São Paulo (vários anos). 
Tabela A. 2

Vendas da M. Dedini S.A. Metalúrgica, por produtos, 1950-1961 (preços correntes em Cr\$)

\begin{tabular}{|c|c|c|c|c|c|c|c|c|c|c|c|c|}
\hline Vendas & 1950 & 1951 & 1952 & 1953 & 1954 & 1955 & 1956 & 1957 & 1958 & 1959 & 1960 & 1961 \\
\hline a) peças & 6.168 .175 & 8.012 .358 & 11.080 .188 & 13.562 .769 & 20.089 .597 & 23.053 .296 & 34.027 .448 & 39.700 .458 & 52.177 .475 & 84.237 .620 & 95.651 .805 & $\overline{161.081 .491}$ \\
\hline peças fundidas de ferro & 3.944 .014 & 4.875 .535 & 7.879 .835 & 8.807 .183 & 5.721 .013 & & 23.205 .712 & 22.500 .895 & 14.027.987 & & & \\
\hline peças fundidas de aço & 1.870 .514 & 2.614 .278 & 2.614 .949 & 3.848 .292 & 1.277 .722 & & 9.895 .031 & 15.542 .941 & 34.208 .516 & & & \\
\hline las fundidas de bronze & 353.647 & 522.546 & 585.405 & 907.294 & 13.090 .862 & & 926.706 & 1.656 .622 & 3.940 .972 & & & \\
\hline b) máquinas & 62.465 .998 & 85.657 .905 & 114.547 .754 & 88.257 .461 & 107.417 .923 & 114.072 .206 & 144.743 .886 & 224.593.280 & 234.433.329 & 292.871.584 & 366.852 .214 & 631.380 .958 \\
\hline moendas de cana & 24.344 .000 & 29.787 .800 & 36.856 .743 & 34.346 .347 & 45.661 .000 & & 42.678 .000 & 84.718 .000 & 120.737 .500 & & & \\
\hline mbas & 2.018 .000 & 2.686 .100 & 4.578 .200 & 8.527 .885 & 5.370 .690 & & 5.432 .857 & 6.745 .106 & 9.844 .415 & & & \\
\hline caldeiras & 11.595 .617 & 16.542 .700 & 23.563 .857 & 17.379 .000 & 28.375 .500 & & 48.561 .040 & 56.825 .310 & 49.280 .300 & & & \\
\hline aparellhos para usinas & 24.508 .381 & 36.641 .305 & 49.548 .955 & 28.004.229 & 28.010 .733 & & 48.071 .989 & 76.304 .864 & 54.571 .114 & & & \\
\hline c) veículos & 1.800 & & & & & & & & & & & \\
\hline d) departamentos (loja) & 7.399 .558 & 14.614 .928 & 17.471.209 & 29.954.311 & 18.120 .968 & 17.290 .683 & 12.151 .580 & 15.229 .479 & 44.989.631 & 56.518 .752 & 73.698 .763 & 115.214 .342 \\
\hline e) diversos & 11.754 .847 & 28.479.187 & 43.497 .261 & 41.947.416 & 54.181 .374 & 53.201.335 & 48.782 .076 & 76.835 .692 & 242.376 .702 & 734.494.511 & 744.892 .1941 & 1.088 .377 .183 \\
\hline consertos & 674.486 & 663.037 & 1.050 .843 & 1.798 .683 & 3.691 .796 & & 2.351 .303 & 4.209.120 & 4.436 .016 & & & \\
\hline laminados & & & & & & & & & 88.836 .453 & & & \\
\hline máquinas reformadas & 1.300 .865 & 3.175 .278 & 2.874 .955 & 1.682 .863 & 2.150 .919 & & 2.678 .496 & 5.415 .143 & 38.659 .082 & & & \\
\hline mercador & 2.309.094 & 3.989.484 & 7.955 .217 & 6.904 .508 & 13.313 .970 & & 6.255 .501 & 8.510 .593 & 12.048 .229 & & & \\
\hline materiais velhos & 608.738 & 531.094 & 1.242 .233 & 1.334 .106 & 542.196 & & 422.901 & 221.653 & 7.068 .282 & & & \\
\hline produtos diversos & 6.861 .664 & 18.626 .860 & 26.148 .262 & 22.440 .208 & 25.694 .895 & & 27.676 .105 & 49.646 .395 & 77.066 .086 & & & \\
\hline pregos, porcas, parafusos & & 1.493 .435 & 4.225 .751 & 7.787 .048 & 8.640 .217 & & 5.165 .793 & 1.389 .335 & 9.418 .709 & & & \\
\hline tubos & & & & & 147.382 & & 11.414 & & & & & \\
\hline válvulas & & & & & & & 4.220 .564 & 5.343 .453 & 4.843 .845 & & & \\
\hline produção própria & & & & & & & & 2.100 .000 & & & & \\
\hline
\end{tabular}

Fonte: São Paulo. Diário Oficial de São Paulo (vários anos).

Tabela A.3

Balanço patrimonial e demonstração da conta lucros e perdas da Máquinas Agrícolas Romi S.A., 1955-1961

Balanço Patrimonial da Romi (em Cr\$)

\begin{tabular}{|c|c|c|c|c|c|c|c|}
\hline & 1955 & 1956 & 1957 & 1958 & 1959 & 1960 & 1961 \\
\hline Ativo Circulante & 145.660 .894 & 198.990 .508 & 239.978 .555 & 341.645 .500 & 391.997 .473 & 561.424 .456 & 823.348.757 \\
\hline Disponível (Caixas e Bancos) & 7.151 .594 & 6.546 .350 & 13.959 .140 & 18.085 .753 & 56.825 .700 & 72.362 .417 & 52.940 .556 \\
\hline Realizável & 107.536 .464 & 158.641 .718 & 195.266 .693 & 288.319 .094 & 302.456 .119 & 445.770 .040 & 715.714 .100 \\
\hline Contas de Compensação ) & 30.972 .836 & 33.802 .440 & 30.752 .721 & 35.240 .653 & 32.715 .655 & 43.291 .999 & 54.485 .100 \\
\hline Realizável a longo prazo (Investimento) & & & & & & & 209.000 \\
\hline Ativo Permanente & 72.094.030 & 101.488 .098 & 116.650 .673 & 143.995.339 & 198.509.896 & 660.341 .104 & 755.471.822 \\
\hline Imobilizado & 71.270 .708 & 99.800 .294 & 114.862 .305 & 141.429 .988 & 193.413 .350 & 648.654 .443 & 744.503 .806 \\
\hline Resultado Pendente & 823.321 & 1.687 .804 & 1.788 .369 & 2.565 .351 & 5.096 .546 & 11.686 .660 & 10.968 .016 \\
\hline Ativo Total & 217.754 .924 & 300.478 .606 & 356.629 .228 & 485.640.839 & 590.507 .369 & 1.221.765.560 & 1.578.820.578 \\
\hline Passivo Circulante & 92.725 .737 & 124.531.518 & 133.530.111 & 210.417 .788 & 204.793.335 & 333.470 .513 & 575.312.208 \\
\hline Exigível (Contas Bancárias, Fornecedores) & 40.573 .502 & 62.229 .051 & 69.113 .348 & 124.722 .248 & 108.925 .052 & 181.128 .199 & 329.029 .010 \\
\hline Contas de Compensação & 30.972 .836 & 33.803 .418 & 30.752 .721 & 35.240 .653 & 32.715 .655 & 43.291 .999 & 54.485 .100 \\
\hline Provisões & 21.179 .399 & 28.499 .048 & 33.664 .042 & 49.940 .804 & 62.324 .617 & 108.253 .736 & 191.550 .092 \\
\hline Resultado Pendente (Juros a vencer) & & & & 514.082 & 828.011 & 796.578 & 248.005 \\
\hline
\end{tabular}

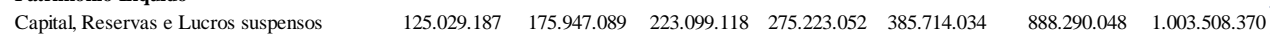

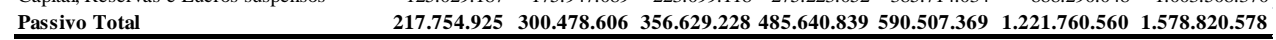

\begin{tabular}{|c|c|c|c|c|c|c|c|}
\hline & 1955 & 1956 & 1957 & 1958 & 1959 & 1960 & 1961 \\
\hline Resultado Industrial (Lucro Bruto Apurado) & 67.772 .085 & 112.856 .587 & 79.152 .776 & 132.778 .303 & 171.429 .753 & 264.646 .863 & 402.975 .278 \\
\hline Receita Extraordinária & 7.556 .301 & 11.122 .463 & 13.216 .471 & 14.456 .246 & 26.454 .970 & 28.341 .239 & 14.202 .156 \\
\hline Saldo Anterior & & & 32.169 .169 & 63.139 .179 & & 166.683 .793 & 252.891 .040 \\
\hline Valor Transferido de Provisões & & & 547.120 & 726.500 & & & 31.812 .953 \\
\hline Crédito Total & 75.328.386 & 123.979 .050 & 125.085.535 & 211.100 .228 & 197.884 .723 & 459.671.895 & 701.881.427 \\
\hline \multicolumn{8}{|l|}{ Débito } \\
\hline Despesas gerais & 35.034 .259 & 90.116 .787 & 60.345 .152 & 98.919 .941 & 137.101.316 & 202.243 .632 & 136.729 .885 \\
\hline Fundo de reserva legal ( $5 \%)$ & 2.012 .206 & 1.693 .114 & 1.601 .205 & 2.415 .730 & 3.039 .170 & 4.537.224 & 5.745 .916 \\
\hline Saldo a disposição da Assembléia & 38.231 .921 & 32.169 .169 & 63.139 .179 & 109.764 .556 & 57.744 .236 & 252.890 .980 & 362.063 .446 \\
\hline Despesas tributárias (impostos e taxas) & & & & & & & 81.003 .452 \\
\hline Amortização do Ativo (depreciações) & & & & & & & 70.756 .102 \\
\hline Provisões (para contas incobráveis) & & & & & & & 45.582 .625 \\
\hline a) Saldo Anterior & & & 32.716 .289 & 63.865 .679 & & 166.683 .793 & 252.891 .040 \\
\hline b) Saldo deste exercício & 38.231 .921 & 32.169 .169 & 32.024 .095 & 48.314 .608 & 57.744 .236 & 90.744 .471 & 114.918 .323 \\
\hline Provisão de Imposto de Renda & & & & & 18.461 .688 & & \\
\hline Lucros Suspensos & & & & & 39.282 .549 & & \\
\hline Débito Total & 75.278 .386 & 123.979 .070 & 125.085.535 & 211.100 .228 & 197.884 .723 & 459.671.835 & 701.881.427 \\
\hline
\end{tabular}

Fonte: São Paulo. Diário Oficial de São Paulo (vários anos). 